\title{
Hierarchical Design of Extraction-Distillation Processes Using Short-Cut Apparatus Models with Piece-Wise Linearized Thermodynamics
}

\author{
M. Kaul, J. Burger*, H. Hasse \\ University of Kaiserslautern, Laboratory of Engineering Thermodynamics, \\ Erwin-Schrödingerstraße 44, 67663 Kaiserslautern, Germany
}

\begin{abstract}
A hierarchical optimization approach for the conceptual design of extractiondistillation processes is presented. The approach includes the solvent selection and flowsheet synthesis using pinch-based short-cut apparatus models which take into account of the material balances and piece-wise linearized thermodynamics (MLT models) and is limited to ternary systems. MLT models enable fast and robust identification of feasible flowsheet-solvent combinations and optimization thereof. Performant solvents are found by assessing process stream tables. Promising solvent-flowsheet combinations are evaluated using flowsheet simulation with detailed models, whereby the MLT results are in good agreement with the results of the detailed models. The approach is presented along an example of the separation of acetic acid and water.
\end{abstract}

Keywords: short-cut models, extraction-distillation process, solvent selection, flowsheet synthesis, conceptual design

\section{Introduction}

During conceptual design of extraction processes, extraction solvents have to be selected, assessed and compared. Thereby it is crucial to consider not only the performance of a solvent during the extraction step but also the work-up

\footnotetext{
*Corresponding author. Tel: +49 6312054028

Email adress: jakob.burger@mv.uni-kl.de (J. Burger)
} 
of extract and raffinate where often distillation is used to recover the solvent and purify the products. The literature describes heuristics (for examples see $[1,2,3])$ which define quantitative thermodynamic performance indicators to assess the suitability of a certain solvent for a given separation task. These indicators involve measures for the capacity and selectivity of a solvent which are based on the specific thermodynamic properties such as the width of the miscibility gap or the activity coefficient at infinite dilution. However, there is no direct relation between these indicators and real process objectives such as solvent flow rates or operating costs. Therefore it is desirable to select solvents based on simulations of the entire process also including solvent recovery and recycle.

Applying rigorous flowsheet simulation based on MESH equations (mass, equilibrium, summation and enthalpy equations) to the task of flowsheet synthesis and solvent selection is cumbersome due to computational expense and convergence problems. Simultaneous solvent selection and flowsheet optimization using MESH equations is thus rarely described in the literature. One of the examples are Stavrou et al. [4] who describe such an integrated approach for solvent design and process optimization using rigorous simulation for absorption.

An often used compromise in the conceptual design phase is the use of shortcut models that require less computational efforts in comparison to MESHmodels at expense of a lower accuracy. The short-cut models are here divided in two categories: models with and without thermodynamic simplification (in the latter case, only the apparatus model is simplified but not the physicalproperty model).

There are numerous approaches that use thermodynamic simplification in conceptual design. For example, the well-known Fenske-Underwood-Gilliland method $[5,6,7]$ for the design of distillation columns under the assumption of constant relative volatilities. A method for absorption column and desorption column design based on thermodynamic simplification is described by Notz et al. [8]. 
Methods without thermodynamic simplifications typically determine the maximum achievable apparatus performance which is limited by thermodynamic restrictions. Such short-cut models for distillation columns are usually based on the assumptions of infinite column height $([9,10])$ sometimes combined with total reflux (see, e.g. the $\infty / \infty$-method for distillation columns $[11,12]$ ).

Apparatuses of infinite height are controlled by pinches, zones of constant concentrations and vanishing driving forces. To analyze the pinch behavior for isothermal extraction columns Minotti et al.[13] introduced the nonlinear pinch equations and the pinch analysis for mixtures of up to four components. Using the method, they compare several flowsheets for an extraction-distillation processes for one solvent and a given separation task [14]. Redepenning and Marquardt [15] proposed an extension of the pinch analysis for isothermal extraction columns applicable to multi-component mixtures. For a given flowsheet Scheffczyk et al. [16] applied this method for a solvent screening procedure. A short-cut model for adiabatic absorption columns based on pinch equations was recently published by Redepenning and Marquardt [17]. Solving the pinch equations involves solving the equations that describe the nonlinear thermodynamics. Typically, the use of continuation methods is suggested for this task $[14,15]$. They require careful initialization to obtain a correct solution [15].

A different approach was suggested by Ryll et al. [18, 19, 20]. Besides infinite height of the apparatuses, also infinite reflux ratio is assumed in distillation columns, leading to further simplifications in the models which will be referred to as MLT models in the sequel. These models combine Material balances with piece-wise Linear Thermodynamics and imply a pre-calculation step in which every type of apparatus (e.g. reactor, distillation column, extraction column) is considered independently from the others. Given a specific mixture and its thermodynamic property data, the attainable products of the apparatus are determined under the assumption of infinite apparatus size, i.e. the occurrence of a pinch. The results are stored in piece-wise linear form whose complexity depends on the non-ideality of the thermodynamics, the number of components in the mixture and the desired accuracy of the linear approximation. The linear 
form of the results enables robust flowsheet evaluations and optimizations later on. The pre-calculation step is independent of the process in which the apparatus is used and has to be done only once for every type of apparatus and every studied mixture. The pre-calculation steps and models are described in detail for equilibrium reactors [20], distillation columns of total reflux [19], decanters [19], and extraction columns [21].

Similar to the other short-cut methods described above, simulations with the MLT models yield the stream table of the process and thus provide quantitative measures of the process performance. Naturally, using infinitely sized apparatus yields only optimistic estimates of the streams, but earlier literature studies show that the estimates are in many cases not far off when compared to more detailed simulations with MESH equations of apparatus with finite size [22, 23, 24]. The stream tables obtained with the MLT models serve not only as basis for process assessment but also as excellent start values for following detailed simulations and optimizations.

Marquardt et al. [25] present a general hierarchical framework to employ pinch-based and other short-cut models as systematic step in process design. This framework has been applied to several process examples, including extractive distillation [26], crystallization [27], distillation [23], absorption [24], and hybrid extraction-distillation [28]. In the same spirit, the present work presents a hierarchical approach for the design of extraction-distillation based on MLT models as short-cut models, namely the MLT models for extraction columns and for distillation columns of total reflux and infinite height. The MLT model for the extraction column is based on the Slope Curve Method (SCM) which is limited to ternary mixtures. Therefore, using the SCM the hierarchical approach is restricted to ternary mixtures. However, the hierarchical approach itself is not limited regarding the number of components. The MLT models enable a swift systematic and robust feasibility assessment of several flowsheets options for a given list of solvent candidates. For feasible flowsheet-solvent combinations the solvent cycle rate is minimized. The most promising flowsheet-solvent combinations are selected and optimized using a detailed equilibrium stage model 
implemented in a standard process simulator in a second step. The approach is illustrated using the extractive separation of acetic acid and water as an example.

\section{Methodology}

The conceptual design of a process to separate a given binary feed mixture by extraction and subsequent work-up of extract and raffinate via distillation is considered. In the work-up, the solvent shall be recovered for recycle to the extraction and the two components of the feed mixture shall be recovered separately.

The design task is solved by a hierarchical optimization approach that encompasses both the solvent selection and flowsheet itself. The procedure consists of seven steps, which are illustrated in Figure 1 and explained one by one in the sequel. 


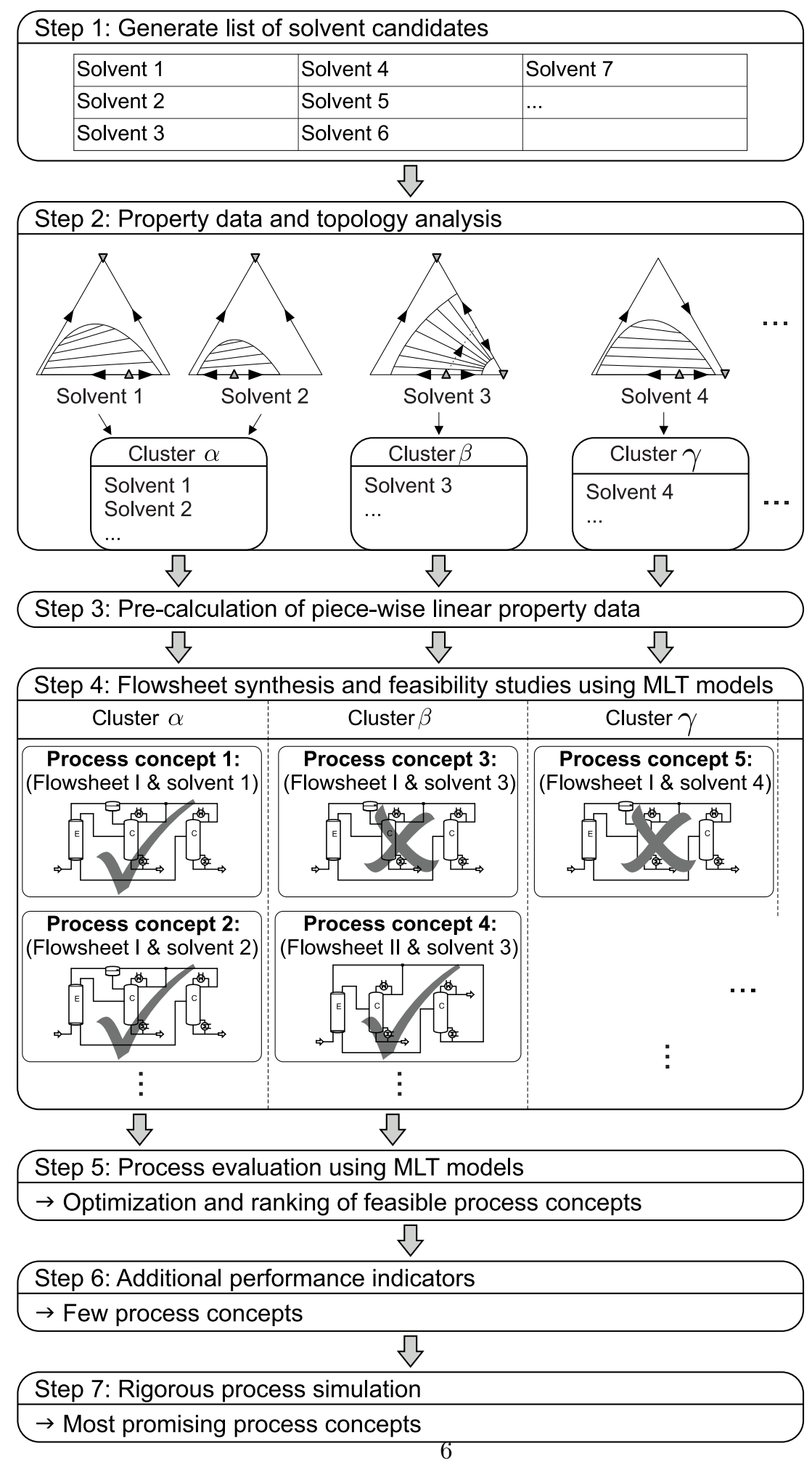

Figure 1: Hierarchical approach for the integrated solvent selection and flowsheet synthesis of extraction-distillation processes. 


\section{Step 1: Generate list of solvent candidates}

A list of solvents is compiled either from a database, from literature research or via methods of computer-aided molecular design (CAMD) [29, 30, 31]. For a feasible solvent, the ternary system of the two components of the feed and the solvent must exhibit a liquid-liquid phase split. A thermodynamic model of the liquid-liquid equilibrium (LLE) in all ternary systems has to be available for the computations. If neither such a model nor experimental data for a model fit are available then methods for property prediction (e.g. UNIFAC or COSMO-RS) can be used.

\section{Step 2: Property data and topology analysis}

The property data required for the MLT models are compiled and classified. Modeling extraction-distillation process by MLT models requires a model of the LLE and the topology of the vapor-liquid equilibrium (VLE) diagram (residue curve diagram) as well as quantitative information on the distillation boundaries, if present. That information can be obtained from a VLE model or in the absence of distillation boundaries from experimental data. For different solvents or different conditions different topologies of the LLE and VLE may be obtained. Ternary systems that exhibit a common topology of the VLE and the LLE are grouped together in clusters. These clusters enable a structured flowsheet design in the next step.

Step 3: Pre-calculation of piece-wise linear property data

MLT models require the property data of VLE and LLE in a special form. In particular, the LLE phase envelope and distillation boundaries (if any) have to be discretizised into piece-wise linear segments. Feasible separation splits of extraction column and distillation column have to be defined for every ternary system. This step is discussed in detail in the next section.

Step 4: Flowsheet synthesis and feasibility studies using MLT models

For each of the clusters feasible flowsheets are designed. This step is interactive and can be subjective based on the preference of the designer. The 
designer suggests a flowsheet. The feasibility of the proposed flowsheet is assessed by simulations with the MLT models. Thereby, one element of the cluster is taken as representative for the cluster. Since the MLT models are robust, nonconvergence is regarded as equivalent to infeasibility. Depending on the result, the designer can modify the flowsheet or suggest an alternative flowsheet. There might be several feasible flowsheets for one cluster. Also, the designer might not come up with any feasible flowsheet for a cluster. In this case, the cluster is considered no longer.

It is generally not possible to compare simple solvents for given separation task but rather combinations of solvent and flowsheet must be compared. Such a combination is called "process concept" in the following.

\section{Step 5: Process evaluation using MLT models}

MLT models have a low number of degrees of freedom, e.g. the distillateto-feed ratio is the only degree of freedom in an $\infty / \infty$ distillation column [18]. During the feasibility study in Step 4 these degrees of freedom are not constrained. In Step 5, which is described now, these degrees of freedom are used as variables to optimize the studied process concepts. The optimization may be single-objective or multi-objective. Objectives must be chosen so that they can be calculated from the process stream table e.g. the overall cycle flow rate or the solvent loss. The choice of the objectives may depend on the designers preference. If objectives are used that exist in all process concepts, then a ranking of the different concepts with respect to these objectives is possible. Unattractive process concepts are rejected.

Note that for a single solvent as well as for a single flowsheet different process concepts may be feasible.

\section{Step 6: Additional performance indicators}

The remaining process concepts are evaluated using additional performance indicators, which take into account properties not considered in MLT models. These properties may be fluid properties such as coalescence behavior, density 
differences, interfacial tension, or viscosity [1] or other indicators like price of the solvent, toxicity, etc..

\section{Step 7: Rigorous process simulation}

In the previous steps the number of solvents and process concepts was gradually reduced. The most promising ones are evaluated in rigorous process simulation using the MESH-equations. For the rigorous simulation, additional property data are required and additional degrees of freedom that are not existent for the MLT models have to be specified (e.g. number of equilibrium stages of the columns). The stream tables of the MLT simulations serve as starting values for the rigorous simulations.

\section{MLT models}

The MLT models for distillation columns, extraction columns, decanter and mixer are applied in this work. They are briefly described in the following.

\subsection{Distillation column}

The MLT model as presented by Ryll et al. [18] is adopted in this work. An isobaric distillation column with a single feed $(\mathrm{F})$ and two product streams, the distillate (D) and the bottom (B) stream, is considered. An infinite number of equilibrium stages $(N=\infty$ for rectifying and stripping section) and an infinite

reflux ratio $(R=\infty)$ are assumed. For given $\mathrm{F}$ (composition $\mathbf{x}^{\mathrm{F}}$ and flow rate $\dot{n}^{\mathrm{F}}$ ) one degree of freedom remains for the MLT distillation column: the ratio of distillate flow rate to feed flow rate:

$$
(\mathrm{D} / \mathrm{F}):=\frac{\dot{n}^{\mathrm{D}}}{\dot{n}^{\mathrm{F}}}, \quad(\mathrm{D} / \mathrm{F}) \in[0,1]
$$

The attainable products for varying $(\mathrm{D} / \mathrm{F})$ are illustrated for a ternary example $1+2+3$ with a low-boiling azeotrope in Figure 2. Component 1 is the global high-boiler (stable node), components 2 and 3 are intermediate boilers (saddle points) and a low-boiling azeotrope in the binary system 2-3 is the global low boiler (unstable node). For the composition of $\mathrm{F}$ shown in Figure 2, the feasible 
compositions of $\mathrm{D}$ and $\mathrm{B}$ are located on the marked piece-wise linear segments. Feasible product pairs are connected by a material balance line through $\mathrm{F}$. The product flow rates $\dot{n}^{\mathrm{D}}$ and $\dot{n}^{\mathrm{B}}$ follow from the lever-rule (material balance). The MLT model combines the column's material balance with conditions ensuring that the products are located in the product regions indicated in the Figure. For the shown ternary mixture, only the boiling sequence of the pure components and the azeotrope (composition and boiling temperature) are relevant as property data. The resulting equations are linear. Details about the equations and the inclusion of more complex VLE topologies are given by Ryll et al. [18].

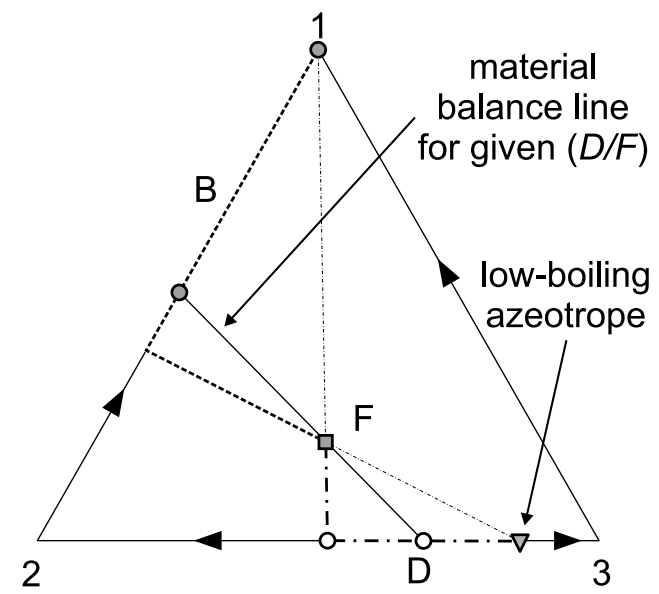

Figure 2: Attainable products of a MLT distillation column with the feed F. ${ }^{-\cdot}$ feasible distillate products $\mathrm{D}, \cdots-\cdots$ feasible bottom products $\mathrm{B}$. D and $\mathrm{B}$ are connected by a material balance line through F.

\subsection{Extraction column}

The MLT model for extraction columns is based on the slope curve method (SCM) presented in our earlier work [21] and considers a counter-current extraction column with an infinite number of stages $(N=\infty)$ at constant temperature and pressure ( $p, t=$ const.). Due to the infinite height at least one pinch occurs. The two streams entering the column are the feed (F) and the solvent (S), the two streams leaving the column are the extract $(\mathrm{E})$ and the raffinate $(\mathrm{R})$. If the compositions and flow rates of $\mathrm{F}$ and $\mathrm{S}\left(\mathbf{x}^{\mathrm{F}}, \mathbf{x}^{\mathrm{S}}, \dot{n}^{\mathrm{F}}\right.$ and $\left.\dot{n}^{\mathrm{S}}\right)$ are given, the 
column has no degree of freedom, the products can be calculated.

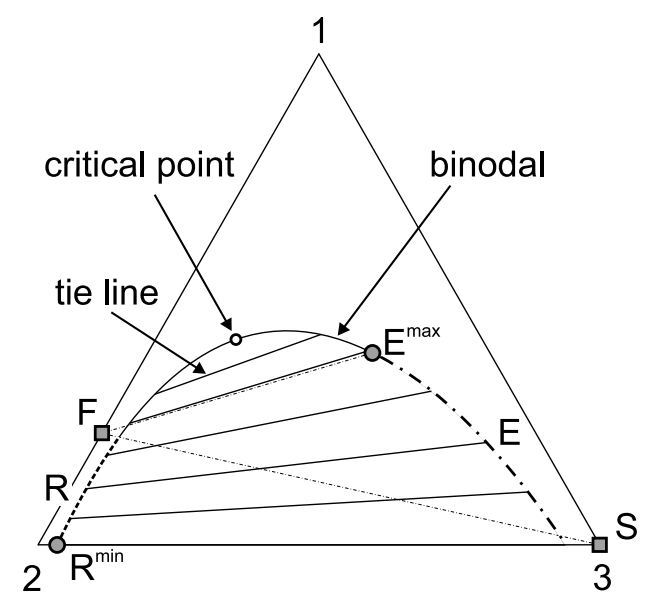

Figure 3: Attainable products of a MLT extraction column with solvent $\mathrm{S}$, feed F, raffinate $\mathrm{R}$ and extract E. --- feasible extract products E, ---- feasible raffinate products $\mathrm{R}$. In case of a feed pinch $\mathrm{E}=\mathrm{E}^{\mathrm{max}}$. In case of a solvent pinch $\mathrm{R}=\mathrm{R}^{\mathrm{min}}$.

In Figure 3, a ternary LLE diagram with solute $(1)+$ carrier $(2)+$ solvent (3) is depicted. Further, exemplary compositions of the feed F (mixture of $1+2$ ) and the solvent $\mathrm{S}$ (pure 3) are given. $\mathrm{E}$ and $\mathrm{R}$ are located on the binodal. For small ratios

$$
(\mathrm{S} / \mathrm{F}):=\frac{\dot{n}^{\mathrm{S}}}{\dot{n}^{\mathrm{F}}}
$$

$\mathrm{E}$ is located on the tie line pointing to $\mathrm{F}$, and a feed pinch occurs $\left(\mathrm{E}^{\max }\right.$ in Figure 3). For large $(\mathrm{S} / \mathrm{F}), \mathrm{R}$ is located at the tie line pointing to $\mathrm{S}$ and $\mathrm{a}$ solvent pinch occurs $\left(\mathrm{R}^{\mathrm{min}}\right.$ in Figure 3$)$. There are some ternary mixtures for which an internal pinch may occur [21]. In case of an internal pinch, neither $\mathrm{E}^{\mathrm{max}}$ nor $\mathrm{R}^{\mathrm{min}}$ are obtained.

The MLT model combines equations for the material balance of the column and conditions ensuring $\mathrm{E}$ and $\mathrm{R}$ are located on the binodal. Further, conditions ensuring a pinch are included. In a pre-calculation step, the binodal is discretizised in linear segments. The coordinates of a discrete number of tie lines are transformed into a special coordinate system, the slope diagram [21]. 
During the simulation of a column, the product compositions are obtained by intersection points of several linear lines in the slope diagram. The calculation is iteration-free and has guaranteed convergence also for the case of an internal pinch. For details the reader is referred to [21].

\subsection{Decanter and mixer}

The MLT models of decanter and mixer comprise the material balances. In addition, the decanter model contains conditions ensuring that the products are in LLE in a formulation as pretended by Ryll et al. [19]. Again, the binodal and the tie lines are required in a piece-wise linearized form.

\section{Case study}

\subsection{Task}

The proposed hierarchical approach is demonstrated using an example: the conceptual design of an extraction-distillation process with the task to separate a binary mixture of water $(\mathrm{W})$ and acetic acid (AA). The separation of $\mathrm{W}+\mathrm{AA}$ by extraction is an interesting subject $[14,32,33,34,35]$ since a separation by distillation is difficult because of the low relative volatility in that system at high water concentrations [14]. The process feed contains only W and AA $\left(x_{\mathrm{AA}}^{\mathrm{F}}=0.127 \mathrm{~mol} / \mathrm{mol}\right)$ its flow rate is $\dot{n}^{\mathrm{F}}=1 \mathrm{kmol} / \mathrm{h}$. The feed conditions are held constant in the study. Other conditions would of course be possible using the approach. The task is to obtain the pure products $\mathrm{W}$ and AA. AA shall be extracted in an extraction column by some solvent. The extract and raffinate shall be worked-up in distillation columns. All apparatuses operate at 1.013 bar. The decanter and the extraction column operate at $25{ }^{\circ} \mathrm{C}$. The simulations and calculations using MLT models were carried out in the software Matlab [36]. 


\subsection{Results}

Step 1: Generate list of solvent candidates

The literature is scanned for solvents for which ternary LLE data in the systems $\mathrm{W}+\mathrm{AA}+$ solvent is available and which have a miscibility gap in the system $\mathrm{W}+$ solvent. 10 solvent candidates which fulfill these requirements are collected in Table 1. This list of solvent candidates could be extended e.g. by application of suitable property prediction methods [37, 38, 30]. However, this is not the focus of the present work.

Table 1: List of solvents considered in the present work. Normal boiling points (NBP) of the pure substances and the heteroazeotropes (Azeo) in the system $\mathrm{W}+$ solvent at 1.013 bar. Classification of the solvents in the clusters $\alpha, \beta$ and $\gamma$. Data from [39].

\begin{tabular}{lcccc}
\hline Component & $t^{\mathrm{NBP}} /{ }^{\circ} \mathrm{C}$ & & & \\
\hline Water & 100.0 & & & \\
Acetic acid & 118.5 & & & \\
\hline Solvent & $t_{\mathrm{S}}^{\mathrm{NBP}} /{ }^{\circ} \mathrm{C}$ & $t_{\mathrm{W}+\mathrm{S}}^{\text {Azeo }} /{ }^{\circ} \mathrm{C}$ & $x_{\mathrm{W}}^{\text {Azeo }} / \mathrm{mol} / \mathrm{mol}$ & $\mathrm{Cluster}$ \\
\hline Chloroform & 61.2 & 56.2 & 0.150 & $\alpha$ \\
Diethyl ether & 34.5 & 34.1 & 0.050 & $\alpha$ \\
Diisopropyl ether & 68.4 & 62.2 & 0.219 & $\alpha$ \\
Ethyl acetate & 77.1 & 70.4 & 0.304 & $\alpha$ \\
Isopropyl acetate & 89.0 & 76.6 & 0.396 & $\alpha$ \\
Methyl tert-butyl ether & 55.1 & 52.4 & 0.121 & $\alpha$ \\
Vinyl acetate & 72.5 & 66.3 & 0.256 & $\alpha$ \\
Diethyl ketone & 101.4 & 82.9 & 0.475 & $\beta$ \\
Dibutyl ether & 141.8 & 95.5 & 0.773 & $\gamma$ \\
4-Methyl-2-pentanol & 130.4 & 94.4 & 0.805 & $\gamma$ \\
\hline
\end{tabular}

Step 2: Property data and topology analysis

For every solvent $\mathrm{S}$ on the list, the ternary system $\mathrm{W}+\mathrm{AA}+\mathrm{S}$ is considered. For all studied solvents, there is a heteroazeotrope in the system $\mathrm{W}+\mathrm{S}$. The azeotropic data for 1.013 bar is included in Table 1. In none of the systems 
$\mathrm{W}+\mathrm{AA}+\mathrm{S}$, other azeotropes occur at 1.013 bar. Furthermore, the studied solvents are completely miscible with AA. None of the systems exhibits distillation boundaries. It is pointed out that no VLE modelling is required for the MLT models. The quantitative information in Table 1 is sufficient for the MLT model of distillation columns.

The LLE in the studied ternary mixtures are calculated using the iso-activity criterion and the UNIQUAC model [40]. The UNIQUAC parameters are taken from the literature (cf. Supporting Information). For all systems a closed miscibility gap with a critical point is obtained for $25^{\circ} \mathrm{C}$.

Based on the topologies of the VLE and LLE of the ternary mixtures, the solvents are divided in solvent clusters, which are defined in Figure 4. The information on the LLE is included in Figure 4 for completeness. As all studied systems have the same LLE topology it is not needed for the classification. Furthermore, also the number of azeotropes is the same for all systems and no distillation boundaries occur. However, the boiling sequence of the pure components and the azeotropes vary, cf. Table 1. According to the boiling sequences, the solvents are grouped into three clusters named $\alpha, \beta, \gamma$ (Figure 4).
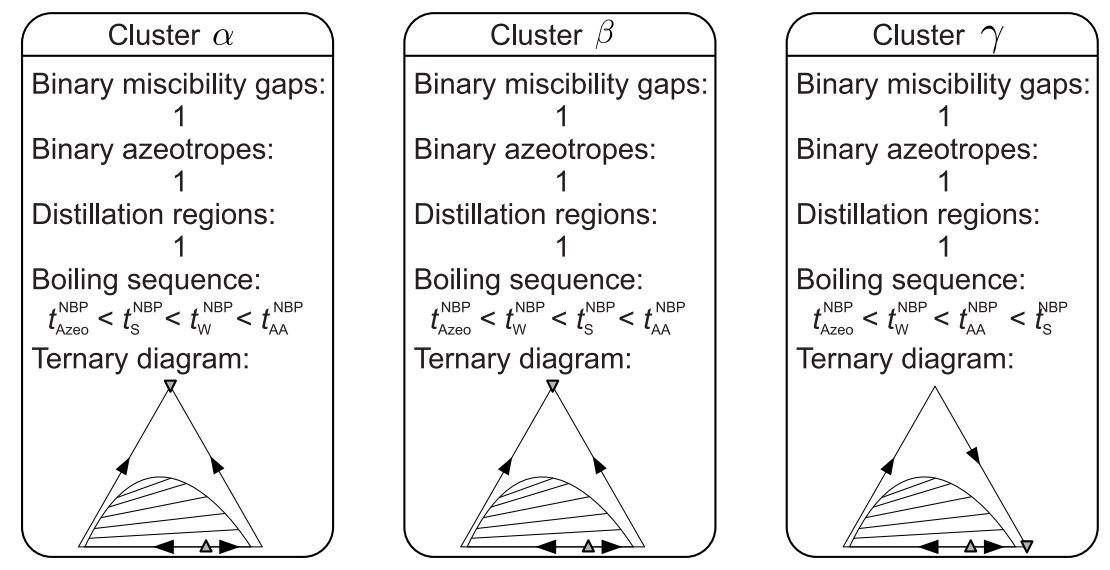

Figure 4: Definition of the applied solvent clusters. 
Step 3: Pre-calculation of piece-wise linear property data

For the MLT extraction column the LLE property data is needed in the form of the discrete slope curves ([21]). For the discretization 1500 tie lines per ternary mixture are used here. This large number poses no problem, since the 1500 tie lines have to be determined only once in the pre-calculation step. Later in the process simulation, a piece-wise model with 1500 discretization point does not cause significant numerical issues.

For the MLT distillation column the experimental VLE data listed in Table 1 include all required property data. No further pre-calculations are necessary.

\section{Step 4: Flowsheet synthesis and feasibility studies using MLT models}

The flowsheet synthesis and feasibility study is discussed here using the solvent diethyl ether (DE) as an example. DE belongs to cluster $\alpha$. For the ternary mixture $\mathrm{W}+\mathrm{AA}+\mathrm{DE}$ the required property data for the MLT models and the process feed (1) are visualized in the ternary diagram in Figure 5. Figure 5 also includes a flowsheet which is discussed in the following (Flowsheet I): an extraction column E1 splits the feed (1) and the solvent (2) into a waterrich raffinate (3) and an acetic acid-rich extract (4). In the distillation columns $\mathrm{C} 1$ and $\mathrm{C} 2$, pure $\mathrm{W}$ and $\mathrm{AA}$ are obtained, respectively. The distillate streams 7 and 8 are mixed and recycled back to the extraction column (solvent stream 2). For reasons of better readability, the shown flowsheet does not show the extraction column in proper orientation for the example. In operation, the lighter solvent would be fed at the bottom and the heavier feed at the top. For the simulations with the MLT model or the equilibrium stage model this is however irrelevant. 
a)

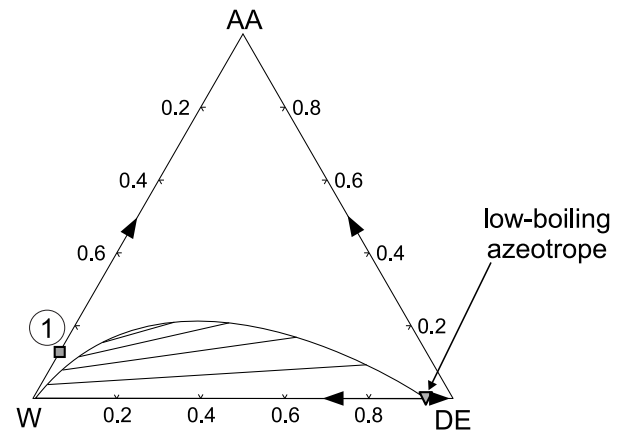

b)

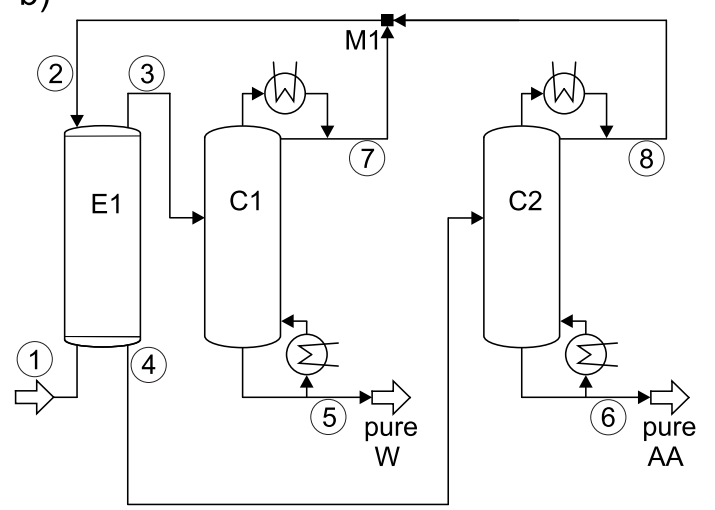

Figure 5: a) LLE and singular points of the residue curve diagram of the system water (W), acetic acid (AA) and diethyl ether (DE) at the studied conditions. Arrows indicate the direction of residue curves in the binary systems. (1) marks the process feed, concentrations in $\mathrm{mol} / \mathrm{mol}$. b) Flowsheet I for the separation of the process feed (1) with the aim to obtain product streams of $\mathrm{W}$ and $\mathrm{AA}$.

Flowsheet I is simulated using MLT models and a sequential-modular approach. The chosen approach is robust as explained in the sequel. The process units are calculated one after another. Knowing the input streams of a unit, the output streams can be calculated with guaranteed convergence. This is proven for the extraction column [21] and the distillation columns [19] elsewhere. Because the distillation columns have one degree of freedom, i.e. the ratio $(\mathrm{D} / \mathrm{F})$, one specification has to be provided to calculate the output streams from the input stream. In the special case of Flowsheet I, the bottom rates of the columns $\mathrm{C} 1$ and $\mathrm{C} 2$ are known a priori because they comprise the flow rates of $\mathrm{W}$ and 
AA, respectively, that are present in the process feed. Thus, the ratio $(\mathrm{D} / \mathrm{F})$ is determined in trivial fashion from the flow rate of the column feed.

Due to the recycle in the process, a tear stream is required in the sequentialmodular approach. Here, the stream 2 is chosen. To avoid problems connected to tear stream convergence, the state variables describing the tear stream $\left(\dot{n}^{(2)}\right.$, $\left.\mathbf{x}^{(2)}\right)$ are simply varied in a parameter variation. For every combination one flowsheet loop is calculated. Three cases are observed:

a) The state variables of stream 2 remain unchanged and the product specifications $x_{\mathrm{W}}^{(5)}=1$ and $x_{\mathrm{AA}}^{(6)}=1$ are met. This corresponds to a feasible process.

b) The state variables of stream 2 remain unchanged and the product specifications $x_{\mathrm{W}}^{(5)}=1$ and $x_{\mathrm{AA}}^{(6)}=1$ are not met. This corresponds to an infeasible process due to failed product specifications.

c) The state variables of stream 2 change after one loop. This corresponds to an infeasible process that cannot be operated even when accepting poor product specifications.

The presented sequential-modular approach is specialized to the concrete flowsheet structure of the given process. A more flexible simulation technique would be a simultaneous-equation-oriented mode in which all MLT model equations are solved at once. Ryll et. al [18, 19, 20] have presented such an approach and have shown how to include the piece-wise linear models in a way that the overall flowsheet problem consists of a set of linear subproblems. To integrate the extraction columns in such a framework additional research is required [21]. This is why in the present work an easy to implement sequential-modular approach was used.

It is found, that only solutions with $x_{\mathrm{AA}}^{(2)}=0$ are feasible. This can be explained: If stream 2 would contain AA, then stream 3 would also and a bottom stream 5 solely containing $\mathrm{W}$ would not be feasible, because AA is the global high-boiler. 


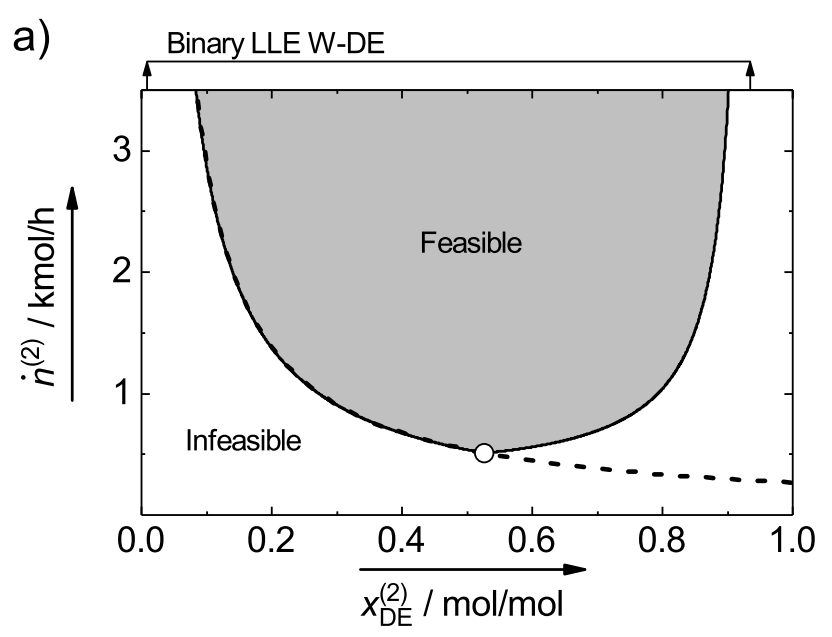

b)

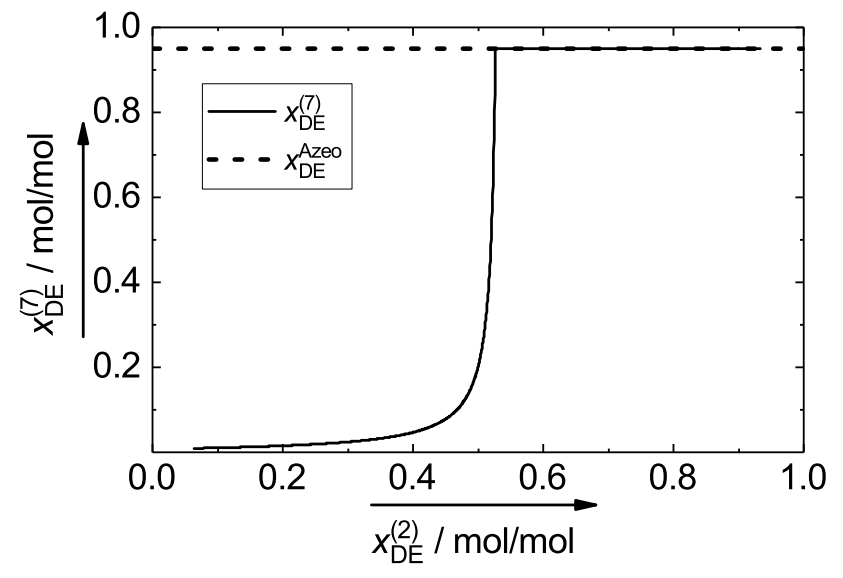

Figure 6: Results of the feasibility study for the process concept Flowsheet I and solvent diethyl ether (DE) and the process concept Flowsheet II and solvent DE. a) Parameter space and feasible parameter combinations. The solid line indicates the limit of feasibility. The dashed line shows the dependence of the minimal solvent flow rate on $x_{\mathrm{DE}}^{(2)}$. That curve determines the limit of feasibility for low values of $x_{\mathrm{DE}}^{(2)}$. The lowest attainable value of $\dot{n}^{(2)}$ is indicated by an open circle. b) Composition of stream 7 at the limit of feasibility.

Figure 6a) shows the results for the parameter study. For each feasible solution, the simulation yields the complete stream table of the process. The border line between feasible and infeasible region in the parameter space marks 
the limit of feasibility (solid line in Figure 6a)). For a given $x_{\mathrm{DE}}^{(2)}$ the solutions below the limit of feasibility are not feasible either due to cases b) or c). The dashed line in Figure 6a) shows the minimum solvent flow rate for a given $x_{\mathrm{DE}}^{(2)}$ to obtain a binary raffinate (stream 3 ), i.e. the minimum solvent flow rate to obtain a solvent pinch in E1 (stream $3=R^{\text {min }}$, cf. Figure 3 ). For low values of $x_{\mathrm{DE}}^{(2)}$ this curve coincides with the limit of feasibility. For high values of $x_{\mathrm{DE}}^{(2)}$ this curve is below the limit of feasibility and the process is obviously restricted by another cause. This cause is explained along Figure $6 \mathrm{~b}$ ) which shows the fraction of DE in stream $7\left(x_{\mathrm{DE}}^{(7)}\right)$ plotted over $x_{\mathrm{DE}}^{(2)}$ for the solutions on the limit of feasibility (solid line in Figure 6a)). Since the feed of column C1 (stream 3) is binary for all feasible solutions, stream 7 is also binary $(\mathrm{W}+\mathrm{DE})$. For high values of $x_{\mathrm{DE}}^{(2)}$, the column $\mathrm{C} 1$ yields an azeotropic distillate composition (cf. Table 1), leading to a second pinch at the column top besides the always present pinch at the column's bottom (due to the pure bottom product). The MLT models show that for high values of $x_{\mathrm{DE}}^{(2)}$ the azeotropic composition can only be reached when the solvent rate $\dot{n}^{(2)}$ is significantly increased compared to the minimum flow rate as required in the extraction column.

At $x_{\mathrm{DE}}^{(2)}=0.527 \mathrm{~mol} / \mathrm{mol}$ the attainable value of $\dot{n}^{(2)}$ is minimal (open circle in Figure 6a)) and the process is limited by the minimum solvent flow rate to obtain a binary raffinate as well as by the azeotropic composition of stream 7 .

For Flowsheet I, stream 2 is located in the binary miscibility gap $\mathrm{W}+\mathrm{DE}$, i.e. $x_{\mathrm{DE}}^{(2)}$ is an overall composition of a two phase stream (cf. Figure 6a)). This is exploited by changing the flowsheet to Flowsheet II which is shown in Figure 7. A decanter is employed to split stream 2 into a solvent-rich and a water-rich phase. The solvent-rich phase (9) is employed as the solvent stream to the extraction column E1. The water-rich phase (10) is recycled to column C1. 


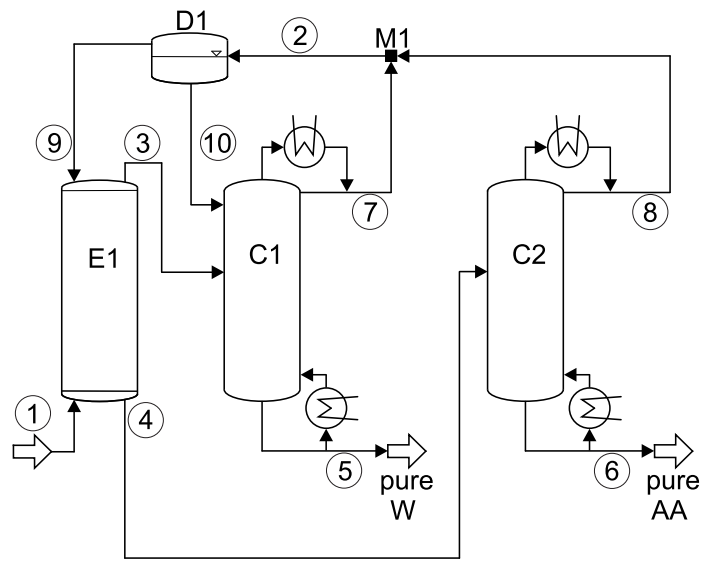

Figure 7: Flowsheet II for the separation of water (W) and acetic acid (AA) with the aim to obtain pure product streams of $\mathrm{W}$ and AA.

The feasibility study is repeated with the same specifications and the same simulation technique as for Flowsheet I. The feasible region for Flowsheet II is found to be identical with that for Flowsheet I shown in Figure 6a). To understand these identical results, imagine stream 10 of Flowsheet II being fed to E1 alongside stream 9. This is the situation of Flowsheet I. The water-rich phase (10) would leave the column E1 immediately with the raffinate (3). Thus, it would be fed to the column $\mathrm{C} 1$ as in Flowsheet II. In Flowsheet II, the raffinate is however smaller than in Flowsheet I. The same holds for the solvent feed to the extraction column (stream 9 in Flowsheet II, stream 2 in Flowsheet I). Also for Flowsheet II, feasible streams 2, 3, 9 and 10 are always binary mixtures of $\mathrm{W}$ and DE.

Since the feasible parameter space is identical for both flowsheets and some streams are generally smaller for Flowsheet II, Flowsheet I is not considered any longer.

Flowsheet II is also feasible for the other solvents of cluster $\alpha$. Also the solvents of cluster $\beta$ yield feasible solutions. In cluster $\beta$, AA remains the global high-boiler. Thus, the feeds to column C1 (stream 3 and stream 10) have to remain binary, and AA can be obtained from the extract in column $\mathrm{C} 2$ at 
the bottom. The resulting parameter spaces reveal a similar limit of feasibility. For the sake of brevity, the discussion is omitted.

For cluster $\gamma$, however, the Flowsheet II is infeasible. No matter what values are chosen for stream 2, the MLT models never yield a feasible process. AA is no longer the high-boiler in the systems of cluster $\gamma$ and thus cannot be separated in the bottom of column C2. For cluster $\gamma$, Flowsheet III (cf. Figure 8b)) is suggested. AA is obtained as distillate of $\mathrm{C} 2$, the rest is identical to Flowsheet II. Also Flowsheet III turns out to be entirely infeasible no matter what composition the stream 2 takes. This is explained by the fact, that AA as an intermediate boiler cannot be obtained as the distillate of a column that is fed with the ternary extract. 
a)

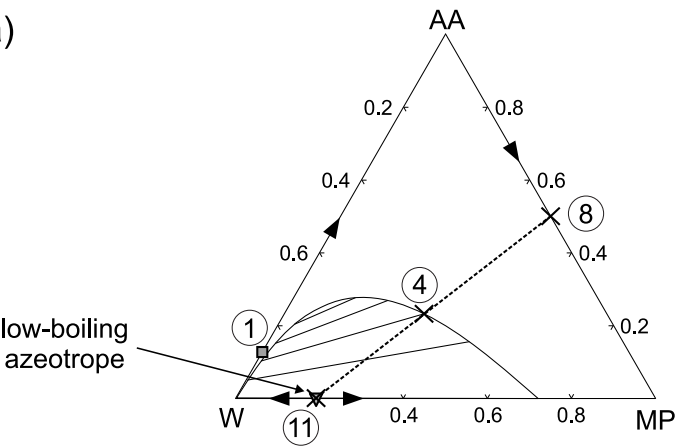

b) Flowsheet III

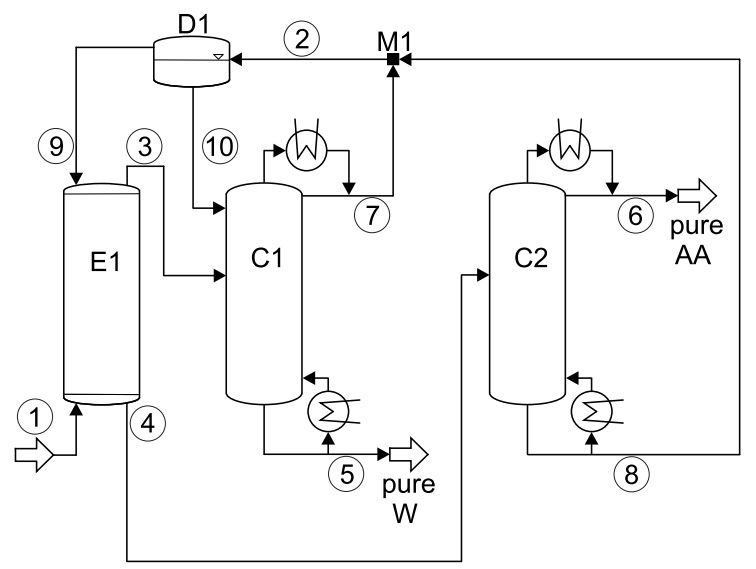

c) Flowsheet IV

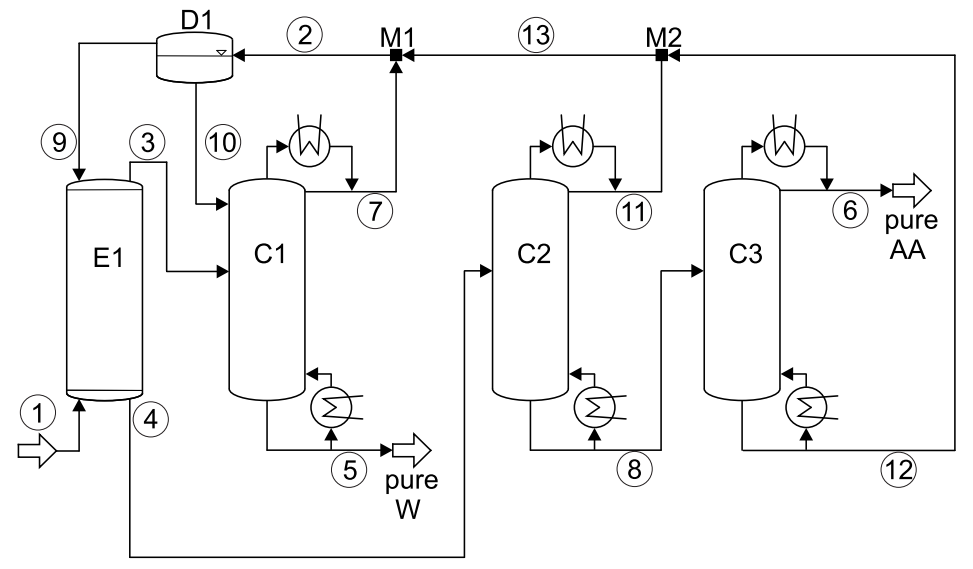

Figure 8: a) LLE and singular points of the residue curve diagram of the system water (W), acetic acid (AA) and 4-methyl-2-pentanol (MP) at the studied conditions (cluster $\gamma$ ). Arrows indicate the direction of residue curves in the binary systems. The encircled numbers mark streams of Flowsheet IV. The straight line indicates an exemplary split of column C2. Concentrations in $\mathrm{mol} / \mathrm{mol}$. b) Flowsheet III and c) Flowsheet IV for the separation of the process feed (1) with the aim to obtain product streams of $\mathrm{W}$ and AA. 
Consequently, the flowsheet is extended. In Flowsheet IV, a third distillation column (column C3) is added to obtain a pure AA product stream (cf. Figure $8 \mathrm{c})$ ). The extract (4) is first split in column C2, where a binary mixture of AA and solvent is obtained as bottom product (8). In column C3 pure AA is obtained as distillate (6). The distillate of columns $\mathrm{C} 1$ and $\mathrm{C} 2$ (stream 7 and stream 11) and the bottom of column C3 (12) are mixed yielding stream 2 which is fed to the decanter D1. The solvent-rich phase (9) is fed to the extraction column E1. The water-rich phase (10) is recycled to C1. As in the other flowsheets, pure $\mathrm{W}$ is obtained from the raffinate as the bottom product of $\mathrm{C} 1$ (5).

For representing the results for cluster $\gamma$ and Flowsheet IV the solvent 4methyl-2-pentanol (MP) is chosen as an example (cf. Figure 8a)). Flowsheet IV is simulated in analogy to Flowsheet I using stream 2 as tear stream and varying its state in a parameter study. Since three distillation columns are passed in the loop, three $(\mathrm{D} / \mathrm{F}) \mathrm{s}$ have to be specified. The $(\mathrm{D} / \mathrm{F}) \mathrm{s}$ of $\mathrm{C} 1$ and $\mathrm{C} 3$ follow, as before, via the material balance from the flow rate of $\mathrm{W}$ and $\mathrm{AA}$ in the feed. The $(\mathrm{D} / \mathrm{F})$ of $\mathrm{C} 2$ is chosen such that the distillate (11) is azeotropic and the bottom (8) is water-free. Such a split is demonstrated in Figure 8a).

The feasible and infeasible parameter combinations (cf. Figure 9a)) and the related limitations follow the same pattern as found for Flowsheet II . For $x_{\mathrm{MP}}^{(2)} \leq 0.349 \mathrm{~mol} / \mathrm{mol}$ the minimum flow rate of stream 2 is caused by the appearance of the solvent pinch leading to a binary $(\mathrm{W}+\mathrm{MP})$ raffinate (stream $3)$. For $x_{\mathrm{MP}}^{(2)} \geq 0.349 \mathrm{~mol} / \mathrm{mol}$ the process is limited by the azeotropic composition of stream 7 (cf. Figure 9b)). For all feasible solutions the streams 2, 3, 7, $9,10,11,12$, and 13 do not contain AA. 


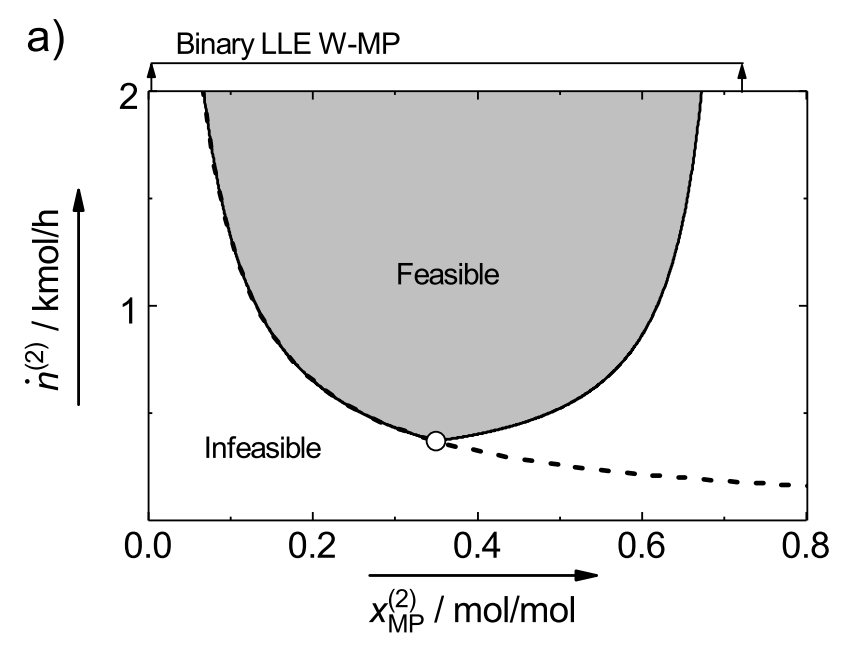

b)

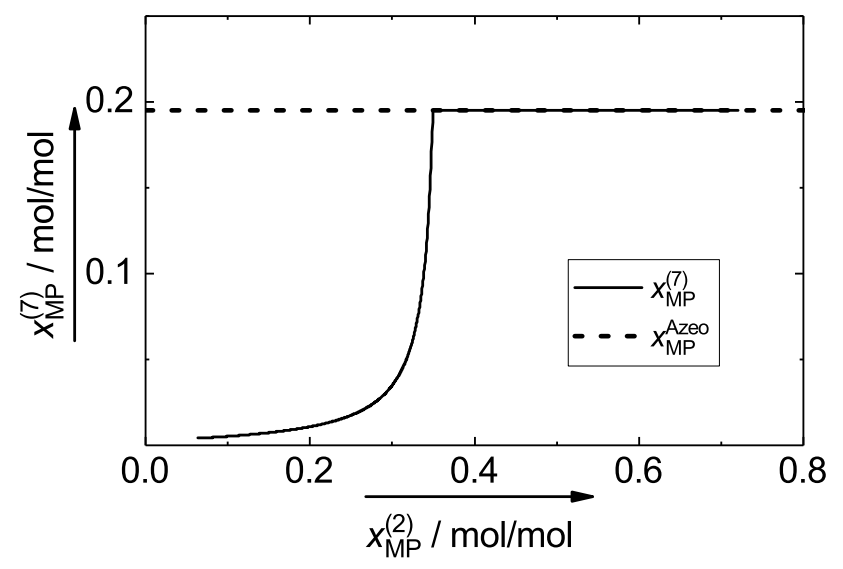

Figure 9: Results of the feasibility study for the process concept Flowsheet IV and solvent 4methyl-2-pentanol (MP). a) Parameter space and feasible parameter combinations. The solid line indicates the limit of feasibility. The dashed line shows the dependence of the minimal solvent flow rate on $x_{\mathrm{MP}}^{(2)}$. That curve determines the limit of feasibility for low values of $x_{\mathrm{MP}}^{(2)}$. The lowest attainable value of $\dot{n}^{(2)}$ is indicated by an open circle. b) Composition of stream 7 at the limit of feasibility.

Step 5: Process evaluation using MLT models

In the previous steps the feasible combinations of solvents and flowsheets, named as process concepts, are identified. For comparing these process concepts 
the molar flow rate of the recycle, stream 2 is chosen as common objective and an optimization problem is formulated as follows and solved for every process concept individually.

$$
\begin{aligned}
\min _{x_{\mathrm{S}}^{(2)}, \dot{n}(2)} & \dot{n}^{(2)} \\
\text { s.t. } & \mathbf{g}\left(x_{\mathrm{S}}^{(2)}, \dot{n}^{(2)}\right)=0 \\
& x_{\mathrm{W}}^{(5)}=1 \\
& x_{\mathrm{AA}}^{(6)}=1 \\
& x_{\mathrm{S}}^{(2)} \in[0 ; 1] \\
& \dot{n}^{(2)} \in \mathbb{R}^{+}
\end{aligned}
$$

Therein the variable $\mathrm{S}$ stands for the solvent of the studied process concept and $\mathrm{g}\left(\mathrm{x}_{\mathrm{S}}^{(2)}, \dot{n}^{(2)}\right)$ includes the material balances and thermodynamic restrictions of the MLT models. Basically, the above optimization finds the solution indicated by the open circle in Figure 6a) and 9a) for every process concept. The results of the optimization procedure are compared for all process concepts in Figure 10. Based on this results, a ranking of process concepts was made. The five process concepts with $\dot{n}^{(2)}$ smaller or equal then the doted vertical line at $0.60 \mathrm{kmol} / \mathrm{h}$ are selected for further steps.

Note that without detailed simulations using a more detailed model and economic evaluation, there is no guarantee that the selected criterion is leading to the economically best results. However, it is rational to narrow down the candidate space, before further extensive studies in the next steps are performed. For completeness, one of the discarded process concepts (Flowsheet II with ethyl acetate) has been carried on to the next steps. The results which are shown in the Supporting Information did confirm that the discarded process concept is also worse in energetic criteria. 


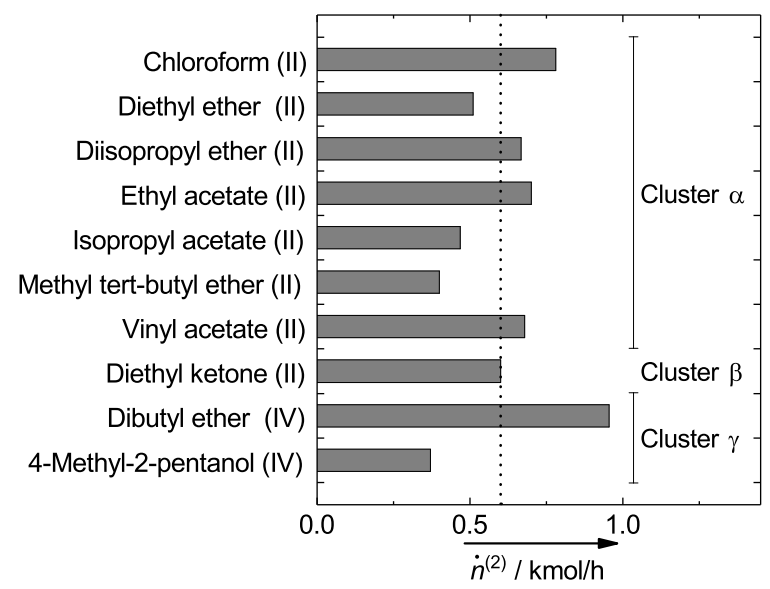

Figure 10: Optimization results for all feasible process concepts using MLT models. The corresponding flowsheet is noted in the brackets. The five process concepts with $\dot{n}^{(2)}$ smaller or equal then the doted line are selected for further steps.

\section{Step 6: Additional performance indicators}

The selected five process concepts are evaluated using additional performance indicators.

These are, on the one hand, pure component properties of the solvents. Examples are the density $(\rho)$ of the pure solvent which should be different from the one of water. This is beneficial in the dynamics of phase separation. Other ones are the melting point $\left(t^{\mathrm{f}}\right)$ and normal boiling point $\left(t^{\mathrm{NBP}}\right)$ which should be not to close to the intended operating conditions in order to avoid problems with solid formation and solvent loss, respectively [1,33]. The numerical values of these properties are shown in Table 2. Based on the table's result no solvent is excluded. 
Table 2: Additional performance indicators for the solvents of the remaining process concepts at operating conditions $\left(25^{\circ} \mathrm{C}\right.$ and 1.013 bar $)$. Data from [39].

\begin{tabular}{llccc}
\hline Cluster & Solvent & $\rho / \mathrm{kg} / \mathrm{m}^{3}$ & $t^{f} /{ }^{\circ} \mathrm{C}$ & $t^{\mathrm{NBP}} /{ }^{\circ} \mathrm{C}$ \\
\hline$\alpha$ & Diethyl ether & 707.6 & -116.3 & 34.5 \\
$\alpha$ & Isopropyl acetate & 862.9 & -73.4 & 89.0 \\
$\alpha$ & Methyl tert-butyl ether & 735.3 & -108.6 & 55.1 \\
$\beta$ & Diethyl ketone & 809.1 & -39.5 & 101.4 \\
$\gamma$ & 4-Methyl-2-pentanol & 801.8 & $-90.0^{\dagger}$ & 130.4 \\
\hline
\end{tabular}

$\dagger[41]$.

Considerations of the pure component properties can be done quite early in the workflow, e.g. after the solvent listing in step 1, or they can be done after the results of the MLT models are available. In the latter case, solvent properties can be combined with information of the stream table yielding more meaningful criteria, as demonstrated here using the example of the relation between enthalpy of vaporization $\left(\Delta h^{\mathrm{vap}}\right)$ of the solvents flow rate for a rough estimation of the energy demand in the distillation. $\Delta h^{\text {vap }}$ alone does not tell much, it has to be considered together with flow rates of column's overhead products and reflux ratios to obtain a meaningful statement regarding energy demand in the distillation. The MLT results do not state anything about reflux ratios (they are assumed to be infinite in the model), but they yield stream data, which can be combined with energetic property data. For example, Table 3 list the minimum energy demand $\dot{Q}^{\text {min }}$ for the distillation columns reboiler based on the assumptions that all overhead products have to evaporated exactly once.

In order to derive statements about the energy demand of the processes and the design of the columns, more detailed process simulations are needed. To determine the minimum energy demand pinch-based shortcut methods could be applied [16]. For the column design more detailed simulations are necessary e.g. based on the equilibrium stage model, which is shown and discussed in the next step. 
Table 3: The minimum energy demand $\left(\dot{Q}^{\text {min }}\right)$ to evaporate all overhead streams of the distillation columns: Flowsheet II: streams 7,8 , Flowsheet IV: streams 6,7 , and $11 . \Delta h^{\text {vap }}$ at $25{ }^{\circ} \mathrm{C}$. [39]

\begin{tabular}{|c|c|c|c|}
\hline Component & $\Delta h^{\mathrm{vap}} / \mathrm{kJ} / \mathrm{mol}$ & & \\
\hline Water & 23.4 & & \\
\hline Acetic acid & 44.0 & & \\
\hline \multicolumn{4}{|c|}{ Process concept } \\
\hline Solvent & Flowsheet & $\Delta h^{\text {vap }} / \mathrm{kJ} / \mathrm{mol}$ & $\dot{Q}^{\text {min }} / \mathrm{kW}$ \\
\hline Diethyl ether & II & 27.2 & 5.0 \\
\hline Isopropyl acetate & II & 37.0 & 5.3 \\
\hline Methyl tert-butyl ether & II & 30.4 & 4.3 \\
\hline Diethyl ketone & II & 35.6 & 6.8 \\
\hline 4-Methyl-2-pentanol & IV & 57.3 & 6.2 \\
\hline
\end{tabular}

Step 7: Rigorous process simulation

The process concepts are simulated and optimized using the more detailed rigorous simulation technique, namely equilibrium-stage models in the commercial process simulation software Aspen Plus [42]. For this purpose, additional thermodynamic property data, such as a VLE model, has to be provided in cumbersome work. For modeling the LLE in the extraction columns and decanters, the UNIQUAC models that form the basis of the MLT models are adopted (cf. Supporting Information). Modeling the VLE for the distillation columns, also the UNIQUAC model but with a second independent set of parameters is used. In the following, we present the results only for the first three process concepts in Table 3. The reason is, that for the other two solvents, the VLE in the binary system acetic acid - solvent could not be modeled with $\mathrm{g}^{\mathrm{E}}$ models in sufficient quality. More advanced thermodynamic modeling would be required that is beyond the scope of the present work. Again, this demonstrates that MLT models run on quite few but accurate (experimental) property data, e.g. boiling order. By contrast, rigorous simulations are cumbersome. For the consideration of the three process concepts, each with another solvent (diethyl ether (DE), isopropyl 
acetate (IPA), and methyl tert-butyl ether (MTBE)), seven binary VLEs need to be modeled. The dimerization of AA in the vapor phase is considered using chemical theory with a dimerization constant given by Büttner and Maurer [43]. The UNIQUAC parameters and a description of the parameter estimation are given in the Supporting Information.

The simulation is done in a two-step procedure. In the Step A, the apparatus are specified to resemble the MLT models closely, i.e. the columns have a large number of stages and the reflux ratios in the distillation columns are large. This step serves the purpose of obtaining a convergent simulation of the process. The MLT stream tables are used as starting values for all streams. Although containing a recycle, and thus a tear stream, the simulations yielded convergence without further ado. In Step B, stage number and reflux ratio are optimized using NQ-curves. In all simulations, the apparatus are operated at 1.013 bar and for decanters and extraction column isothermal operation at $25^{\circ} \mathrm{C}$ is specified. For the specifications in Step A and details of Step B see the Supporting Information.

The final simulation results after the optimization procedure in Step B are presented in Table 4. The purity of the products, stream (5) and (6) is $x_{\mathrm{W}}^{(5)}=0.999 \mathrm{~mol} / \mathrm{mol}$ and $x_{\mathrm{AA}}^{(6)}=0.999 \mathrm{~mol} / \mathrm{mol}$, respectively. The stream tables are visualized and compared to the stream tables obtained from the MLT optimization procedure in Figure 11. The detailed stream tables are reported in the Supporting Information. 

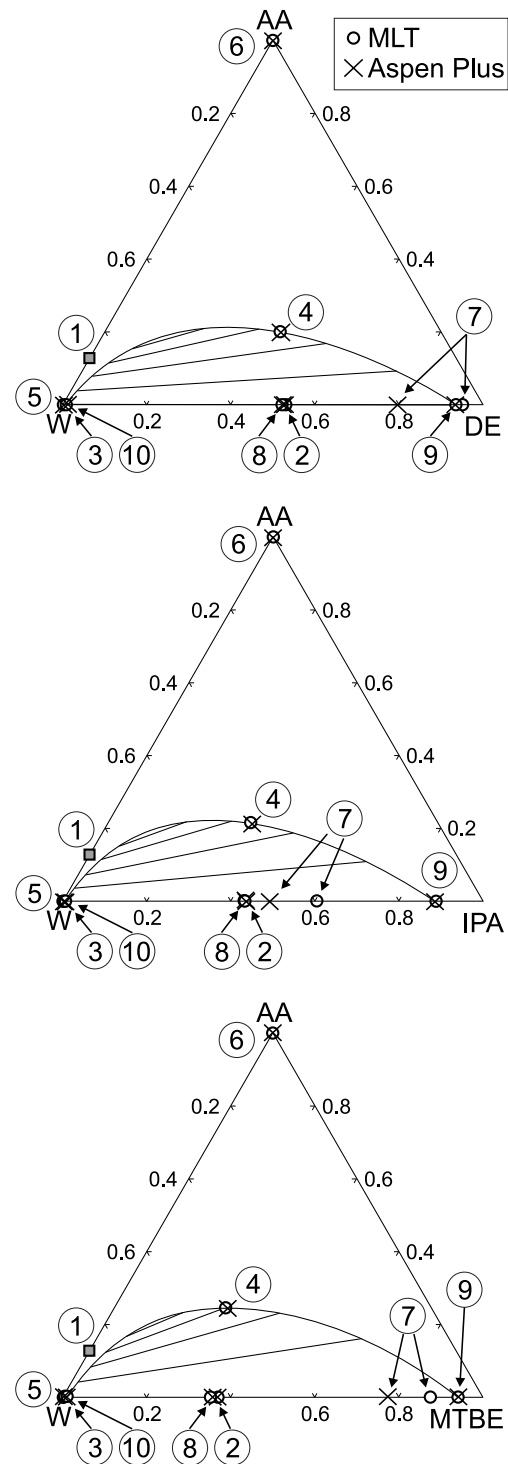

Figure 11: Comparison of the results when using MLT models (circles) and Aspen Plus (crosses). Results of Flowsheet II are shown for the three solvents diethyl ether (DE), isopropyl acetate (IPA) and methyl tert-butyl ether (MTBE). Concentrations are in mol/mol. 
Table 4: Optimization results of the rigorous simulations after Step B for the process concepts comprising Flowsheet II and the listed solvents. The purity of the products, stream 5 and

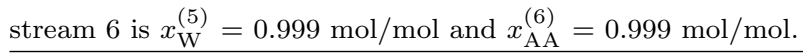

\begin{tabular}{lccc}
\hline Solvent & $\begin{array}{c}\text { Diethyl } \\
\text { ether }\end{array}$ & $\begin{array}{c}\text { Isopropyl } \\
\text { acetate }\end{array}$ & $\begin{array}{c}\text { Methyl } \\
\text { tert-butyl ether }\end{array}$ \\
\hline Number of stages E1 $\left(N^{\mathrm{E} 1}\right)$ & 23 & 21 & 20 \\
Number of stages C1 $\left(N^{\mathrm{C} 1}\right)$ & 7 & 7 & 6 \\
Feed stage C1 $\left(N^{\mathrm{C} 1 \text {,Feed }}\right)$ & 3 & 3 & 3 \\
Number of stages $\mathrm{C} 2\left(N^{\mathrm{C} 2}\right)$ & 45 & 45 & 45 \\
Feed stage C2 $\left(N^{\mathrm{C} 2, \text { Feed }}\right)$ & 31 & 32 & 31 \\
Reflux ratio C1 $\left(R^{\mathrm{C} 1}\right)$ & 3.3 & 4.3 & 3.1 \\
Reflux ratio C2 $\left(R^{\mathrm{C} 2}\right)$ & 7.4 & 8.5 & 9.5 \\
Reboiler duty C1 $\left(\dot{Q}^{\text {Reboiler C1}} / k W\right)$ & 1.7 & 1.8 & 1.7 \\
Reboiler duty $\mathrm{C} 2\left(\dot{Q}^{\text {Reboiler } \mathrm{C} 2} / k W\right)$ & 43.8 & 46.9 & 45.2 \\
Flow rate stream $2\left(\dot{n}^{(2)} / \mathrm{kmol} / \mathrm{h}\right)$ & 0.51 & 0.47 & 0.40 \\
Solvent loss $\left(\dot{n}_{\mathrm{S}}^{(5)}+\dot{n}_{\mathrm{S}}^{(6)} / \mathrm{kmol} / \mathrm{h}\right)$ & $2 \cdot 10^{-11}$ & $1 \cdot 10^{-7}$ & $7 \cdot 10^{-8}$ \\
\hline
\end{tabular}

When comparing the results of the rigorous simulations after Step B) with the results of the MLT simulations, the largest deviation for the process concepts is for the composition of stream 7 (cf. Figure 11). The distillate of $\mathrm{C} 1$ (stream 7) is however a rather small stream, thus small deviations in the column feed lead to large deviations in the composition of stream 7. Apart from that the results of the rigorous simulation and the MLT simulation are in good agreement for the three process concepts as it can be seen in Figure 11.

\section{Discussion and conclusion}

In the proposed hierarchical approach for extraction-distillation processes (Figure 1) the model depth is stepwise increased while the number of process concepts (combinations of certain flowsheet and a certain solvent) is reduced.

MLT models, short-cut models based on maximum apparatus performance and piece-wise linearized thermodynamics are beneficially employed in the ap- 
proach. MLT models do neither require iterations nor continuation methods when calculating output streams from input streams and thus enable robust and reliable feasibility studies and optimizations based on a very small set of thermodynamic properties. The effort for the preparation and execution of the rigorous process simulation is significantly higher than for MLT simulations. Thus MLT models eliminate cumbersome simulation work at an early phase of conceptual design.

For each set of operating conditions ( $p$ and / or $t$ ), one set of pre-calculated property data is required. The degrees of freedom of the MLT models are few. This allows the designer to focus on the most relevant specifications and supports the understanding of the limitations of the process. Beyond information about the feasibility of process concepts, insights about the thermodynamic restrictions of the processes are obtained. MLT simulations provide the quantities of a typical stream table. However, using MLT models a direct consideration of operating cost or investment cost is not possible.

MLT models are not available for all unit operations, and their usage is limited to systems with a small number of components. E.g., the MLT extraction column based on the SCM is limited to ternary mixtures. To extend the application range, MLT models can be combined with apparatus models of a different model depth i.e. other short-cut models, or even rigorous equilibrium stage models. Increased model complexity comes with reduced robustness, though.

The use of MLT models in a hierarchical scheme was demonstrated using the example of an extractive separation of water and acetic acid. Diethyl ether, isopropyl acetate and methyl tert-butyl ether were identified as promising solvents for this task. This result confirms other studies $[14,33,44]$ that have suggested these solvents.

\section{Acknowledgment}

The authors gratefully acknowledge financial support from "Stiftung RheinlandPfalz für Innovation" (Project no. 961-386261/1107). J.B. thanks BASF SE for 
financial support. 


\section{Nomenclature}

List of symbols

$\begin{array}{ll}\rho & \text { density } \\ \Delta h^{\text {vap }} & \text { enthalpy of vaporization } \\ N & \text { number of stages } \\ \dot{n} & \text { molar flow rate } \\ p & \text { pressure } \\ \dot{Q}^{\text {min }} & \text { minimum energy demand for evaporation } \\ R & \text { reflux ratio } \\ t & \text { temperature } \\ t^{f} & \text { melting temperature } \\ t^{\mathrm{NBP}} & \text { normal boiling temperature } \\ x_{\mathrm{A}} & \text { mole fraction component A } \\ \mathbf{x} & \text { molar composition vector }\end{array}$

Abbreviations

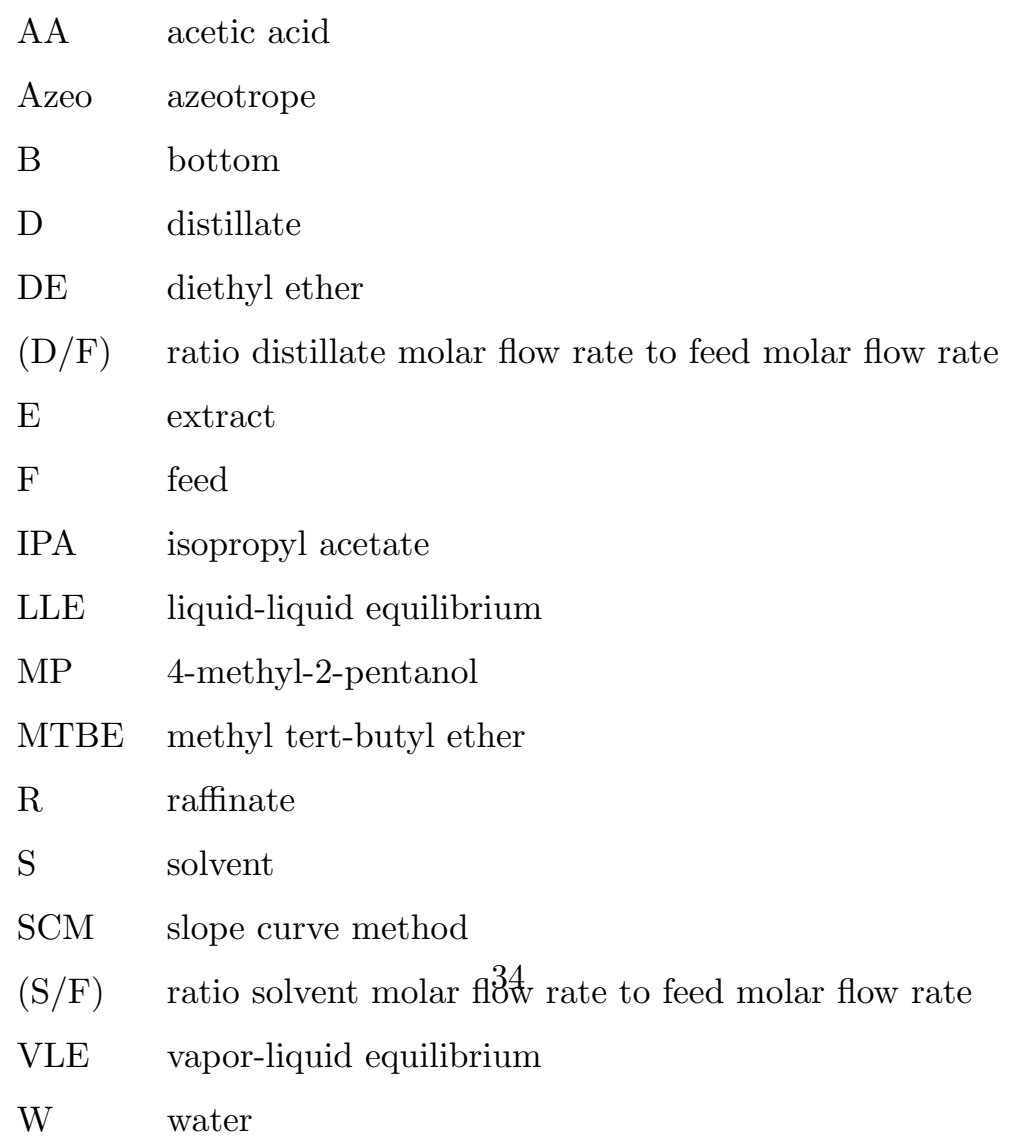




\section{References}

[1] M. J. Hampe, Lösungsmittel-Auswahl bei der Flüssig/Flüssig-Extraktion unter physikalisch-chemischen Aspekten, Chemie Ingenieur Technik 57 (8) (1985) 669-681. doi:10.1002/cite.330570805.

[2] M. C. M. Cockrem, J. H. Flatt, E. N. Lightfoot, Solvent Selection for Extraction from Dilute Solution, Separation Science and Technology 24 (11) (1989) 769-807. doi:10.1080/01496398908049876.

[3] J. Gmehling, A. Schedemann, Selection of Solvents or Solvent Mixtures for Liquid-Liquid Extraction Using Predictive Thermodynamic Models or Access to the Dortmund Data Bank, Industrial \& Engineering Chemistry Research 53 (45) (2014) 17794-17805. doi:10.1021/ie502909k.

[4] M. Stavrou, M. Lampe, A. Bardow, J. Gross, Continuous Molecular Targeting-Computer-Aided Molecular Design (CoMT-CAMD) for Simultaneous Process and Solvent Design for CO2 Capture, Industrial \& Engineering Chemistry Research 53 (46) (2014) 18029-18041. doi:10.1021/ie502924h.

[5] M. R. Fenske, Fractionation of Straight-Run Pennsylvania Gasoline, Industrial \& Engineering Chemistry 24 (5) (1932) 482-485. doi:10.1021/ie50269a003.

[6] A. Underwood, Fractional Distillation of Multicomponent Mixtures, Chemical Engineering Progress 44 (8) (1948) 603-614.

[7] E. R. Gilliland, Multicomponent Rectification Estimation of the Number of Theoretical Plates as a Function of the Reflux Ratio, Industrial \& Engineering Chemistry 32 (9) (1940) 1220-1223. doi:10.1021/ie50369a035.

[8] R. Notz, I. Tönnies, H. P. Mangalapally, S. Hoch, H. Hasse, A ShortCut Method for Assessing Absorbents for Post-Combustion Carbon Dioxide Capture, International Journal of Greenhouse Gas Control 5 (3) (2011) 413-421. doi:10.1016/j.ijggc.2010.03.008. 
[9] J. G. Stichlmair, J. R. Fair, Distillation: Principles and Practice, 1st Edition, Wiley-VCH, New York, USA, 1998.

[10] M. Doherty, M. Malone, Conceptual Design of Distillation Systems, 1st Edition, McGraw-Hill, New York, USA, 2001.

[11] F. B. Petlyuk, V. S. Avet'yan, Investigation of the Rectification of ThreeComponent Mixtures with Infinite Reflux, Theoretical Foundations of Chemical Engineering 5 (1971) 499-507.

[12] L. A. Serafimov, V. Timofeev, M. Balashov, Rectification of Multicomponent Mixtures. II. Local and General Characteristics of the Trajectories of Rectification Processes at Infinite Reflux Ratio, Acta Chimica Academiae Scientiarum Hungaricae 75 (1973) 193-211.

[13] M. Minotti, M. F. Doherty, M. F. Malone, A Geometric Method for the Design of Liquid Extractors, Industrial \& Engineering Chemistry Research 35 (8) (1996) 2672-2681. doi:10.1021/ie950687+.

[14] M. Minotti, M. F. Doherty, M. F. Malone, Economic Tradeoffs for Extraction Systems, Chemical Engineering Research and Design 76 (3) (1998) 361 - 367. doi:http://dx.doi.org/10.1205/026387698524785.

[15] C. Redepenning, S. Recker, W. Marquardt, Pinch-Based Shortcut Method for the Conceptual Design of Isothermal Extraction Columns, AIChE Journal 63 (4) (2017) 1236-1245. doi:10.1002/aic.15523.

[16] J. Scheffczyk, C. Redepenning, C. M. Jens, B. Winter, K. Leonhard, W. Marquardt, A. Bardow, Massive, Automated Solvent Screening for Minimum Energy Demand in Hybrid Extraction-Distillation Using COSMORS, Chemical Engineering Research and Design 115, Part B (2016) 433442. doi:10.1016/j.cherd.2016.09.029.

[17] C. Redepenning, W. Marquardt, Pinch-Based Shortcut Method for the Conceptual Design of Adiabatic Absorption Columns, AIChE Journal 63 (4) (2017) 1213-1225. doi:10.1002/aic.15499. 
[18] O. Ryll, S. Blagov, H. Hasse, $\infty / \infty$-Analysis of Homogeneous Distillation Processes, Chemical Engineering Science 84 (0) (2012) 315 - 332. doi: $10.1016 / j \cdot \operatorname{ces} .2012 .08 .018$.

[19] O. Ryll, S. Blagov, H. Hasse, $\infty / \infty$-Analysis of Heterogeneous Distillation Processes, Chemical Engineering Science 104 (0) (2013) 374 - 388. doi:10.1016/j.ces. 2013.09.012.

[20] O. Ryll, S. Blagov, H. Hasse, Thermodynamic Analysis of Reaction-Distillation Processes Based on Piecewise Linear Models, Chemical Engineering Science $109 \quad(0) \quad(2014) \quad 284 \quad-\quad 295$. doi: $10.1016 / j$.ces . 2014.01 .024 .

[21] J. Burger, M. Kaul, H. Hasse, Slope Curve Method for the Analysis of Separations in Extraction Columns of Infinite Height, Chemical Engineering Science 143 (2016) 105-113. doi:10.1016/j.ces.2015.12.008.

[22] T. Grützner, H. Hasse, N. Lang, M. Siegert, E. Ströfer, Development of a New Industrial Process for Trioxane Production, Chemical Engineering Science 62 (1820) (2007) 5613-5620. doi:10.1016/j.ces.2007.01.047.

[23] J. Burger, E. Ströfer, H. Hasse, Production Process for Diesel Fuel Components Poly(oxymethylene) Dimethyl Ethers from Methane-Based Products by Hierarchical Optimization with Varying Model Depth, Chemical Engineering Research and Design 91 (12) (2013) 2648-2662. doi:10.1016/j.cherd.2013.05.023.

[24] J. Burger, V. Papaioannou, S. Gopinath, G. Jackson, A. Galindo, C. S. Adjiman, A Hierarchical Method to Integrated Solvent and Process Design of Physical CO2 Absorption Using the SAFT- $\gamma$ Mie Approach, AIChE Journal 61 (10) (2015) 3249-3269. doi:10.1002/aic.14838.

[25] W. Marquardt, S. Kossack, K. Kraemer, A Framework for the Systematic Design of Hybrid Separation Processes, Chinese Journal of Chemical Engineering 16 (3) (2008) 333 - 342. 
doi:http://dx.doi.org/10.1016/S1004-9541(08)60084-1.

URL http://www.sciencedirect.com/science/article/pii/S1004954108600841

[26] S. Kossack, K. Kraemer, R. Gani, W. Marquardt, A Systematic Synthesis Framework for Extractive Distillation Processes,

Chemical Engineering Research and Design $86 \quad$ (7) (2008) $781 \quad-\quad 792, \quad<$ ce:title $>$ ECCE-6</ce:title $>$. doi:http://dx.doi.org/10.1016/j.cherd.2008.01.008.

URL http://www.sciencedirect.com/science/article/pii/S0263876208000257

[27] M. B. Franke, N. Nowotny, E. N. Ndocko, A. Górak, J. Strube, Design and Optimization of a Hybrid Distillation/Melt Crystallization Process, AIChE Journal 54 (11) (2008) 2925-2942. doi:10.1002/aic.11605.

[28] K. Kraemer, A. Harwardt, R. Bronneberg, W. Marquardt, Separation of Butanol from Acetone-butanol-ethanol Fermentation by a Hybrid Extraction Distillation $\mathrm{F}$ Computers \& Chemical Engineering $35 \quad$ (5) (2011) 949-963. doi:10.1016/j. compchemeng. 2011.01.028.

URL http://www.sciencedirect.com/science/article/pii/S009813541100038X

[29] E. J. Pretel, P. A. Lpez, S. B. Bottini, E. A. Brignole, Computer-aided molecular design of solvents for separation processes, AIChE Journal 40 (8) (1994) 1349-1360. doi:10.1002/aic.690400808. URL http://onlinelibrary.wiley.com/doi/10.1002/aic.690400808/abstract

[30] P. M. Harper, R. Gani, P. Kolar, T. Ishikawa, Computer-Aided Molecular Design with Combined Molecular Modeling and Group Contribution, Fluid Phase Equilibria 158-160 (1999) 337-347. doi:10.1016/S0378-3812(99)00089-8.

URL http://www.sciencedirect.com/science/article/pii/S0378381299000898

[31] P. M. Harper, R. Gani, A multi-step and multi-level approach for computer aided molecular design, Computers \& Chemical Engineering 24 (2) (2000) 677-683. doi:10.1016/S0098-1354(00)00410-5.

URL http://www.sciencedirect.com/science/article/pii/S0098135400004105 
[32] W. V. Brown, Economics of Recovering Acetic Acid, Chem. Eng. Prog. 59 (10) (1963) 65-68.

[33] S. Kürüm, Z. Fonyo, Ö. M. Kut, Design Strategy for Acetic Acid Recovery, Chemical Engineering Communications 136 (1) (1995) 161-176. doi:10.1080/00986449508936359.

[34] S. Glanz, J. Stichlmair, Energetic Optimization of Distillations in Hybrid Processes, Computers \& Chemical Engineering 19 (1995) 51-56. doi : 10.1016/0098-1354(95)87014-8.

[35] N. García, J. A. Caballero, Economic and Environmental Assessment of Alternatives to the Extraction of Acetic Acid from Water, Industrial \& Engineering Chemistry Research 50 (18) (2011) 10717-10729. doi:10.1021/ie201064x.

[36] Matlab R2014b, MathWorks, Inc., Natick, USA, 2014.

[37] E. A. Brignole, S. Bottini, R. Gani, A Strategy for the Design and Selection of Solvents for Separation Processes., Fluid Phase Equilibria 29 (1986) 125-132.

URL http://www.sciencedirect.com/science/article/pii/0378381286850166

[38] L. Constantinou, K. Bagherpour, R. Gani, J. A. Klein, D. T. Wu, Computer Aided Product Design: Problem Formulations, Methodology and Applications, Computers \& Chemical Engineering 20 (6-7) (1996) 685-702.

URL http://www.sciencedirect.com/science/article/pii/0098135495002022

[39] Dortmunder Data Bank (DDB), DDBST GmbH, Oldenburg, Germany, 2016.

URL http://www.ddbst.de/

[40] D. S. Abrams, J. M. Prausnitz, Statistical Thermodynamics of Liquid Mixtures: A New Expression for the Excess Gibbs Energy of Partly or Completely Miscible Systems, AIChE Journal 21 (1) (1975) 116-128. doi:10.1002/aic.690210115. 
[41] DIPPR. Thermophysical Properties Laboratory - Dippr Project 801, Department of Chemical Engineering Brigham University, Pravo, Utah, 2012.

[42] AspenPlus V8.4, Aspen Technology, Inc., Cambridge, USA, 2013.

[43] R. Büttner, G. Maurer, Dimerisierung einiger organischer Säuren in der Gasphase, Berichte der Bunsengesellschaft für physikalische Chemie 87 (10) (1983) 877-882. doi:10.1002/bbpc.19830871010.

[44] J. A. Caballero, I. E. Grossmann, Rigorous Design of Complex LiquidLiquid Multi-Staged Extractors Combining Mathematical Programming and Process Simulators, in: C. A. O. d. N. Rita Maria de Brito Alves, E. C. Biscaia (Eds.), 10th International Symposium on Process Systems Engineering: Part A, Vol. 27 of Computer Aided Chemical Engineering, Elsevier, 2009, pp. $981-986$. 


\section{Supporting Information}

\section{Property Data}

\subsection{UNIQUAC pure component parameters}

The UNIQUAC pure component parameters listed in Table 1 are applied for modeling the liquid-liquid equilibrium (LLE) and vapor-liquid equiibrium (VLE).

Table 1: UNIQUAC pure component parameters.

\begin{tabular}{lccc}
\hline & $r$ & $q$ & \\
\hline Acetic acid & 2.2024 & 2.072 & {$[1]$} \\
Water & 0.9200 & 1.400 & {$[1]$} \\
Chloroform & 2.8700 & 2.410 & {$[1]$} \\
Dibutyl ether & 6.0925 & 5.176 & {$[1]$} \\
Diethyl ether & 3.3949 & 3.016 & {$[1]$} \\
Diethyl ketone & 3.9223 & 3.416 & {$[1]$} \\
Diisopropyl ether & 4.7423 & 4.088 & {$[2]$} \\
Ethyl acetate & 3.4786 & 3.116 & {$[1]$} \\
Isopropyl acetate & 4.1522 & 3.652 & {$[1]$} \\
Methyl tert-butyl ether & 4.0678 & 3.632 & {$[3]$} \\
4-Methyl-2-pentanol & 4.8015 & 4.124 & {$[1]$} \\
Vinyl acetate & 3.2485 & 2.904 & {$[1]$} \\
\hline
\end{tabular}

\subsection{Binary UNIQUAC parameters for modeling the LLE}

The applied binary UNIQUAC parameters for modeling the LLE are listed in Table 2. The UNIQUAC pure component parameters are given in Table 1. 
Table 2: Binary UNIQUAC parameters $\left(\tau_{i j}=b_{i j} / T\right)$ for the modeling of the liquid-liquid equilibra water $(\mathrm{W})+$ acetic acid $(\mathrm{AA})+$ solvent.

\begin{tabular}{lccccccc}
\hline Component $i$ & $b_{i \mathrm{~W}} / \mathrm{K}$ & $b_{\mathrm{W} i} / \mathrm{K}$ & $b_{i \mathrm{AA}} / \mathrm{K}$ & $b_{\mathrm{AA} i} / \mathrm{K}$ & $b_{\mathrm{WAA}} / \mathrm{K}$ & $b_{\mathrm{AAW}} / \mathrm{K}$ & Ref. \\
\hline Chloroform & -355.890 & -546.800 & -267.800 & 110.570 & 85.939 & -100.200 & {$[1]$} \\
Dibutyl ether & -761.060 & -400.730 & -198.770 & 122.650 & 201.970 & -80.231 & {$[1]$} \\
Diethyl ether & -493.700 & -127.550 & 212.010 & -26.114 & -129.860 & 254.660 & {$[1]$} \\
Diethyl ketone & -374.630 & -102.600 & 153.190 & 85.952 & -147.390 & 310.350 & {$[1]$} \\
Diisopropyl ether & -602.340 & -86.665 & -45.707 & 106.340 & -73.444 & 219.660 & {$[2]$} \\
Ethyl acetate & -376.940 & -97.519 & 212.180 & -29.450 & -188.770 & 259.460 & {$[1]$} \\
Isopropyl acetate & -403.990 & -126.880 & 193.470 & 14.584 & -150.360 & 270.160 & {$[1]$} \\
Methyl tert-butyl ether & -616.590 & -53.960 & -462.250 & 302.960 & 295.700 & -552.510 & {$[3]$} \\
4-Methyl-2-pentanol & -186.840 & -164.930 & 40.585 & 117.170 & -36.804 & 147.250 & {$[1]$} \\
Vinyl acetate & -573.810 & -219.510 & 80.671 & 166.880 & -81.515 & 308.920 & {$[1]$} \\
\hline
\end{tabular}

\subsection{Binary UNIQUAC parameters for modeling the VLE}

The binary UNIQUAC VLE-parameters for the mixture water (W) and acetic acid (AA) are obtained from a fit to experimental data given by Othmer et al. [4] and Brown et al. [5]. The dimerization constant given by [6] is used to consider the dimerization of AA in the vapor phase. The UNIQUAC parameters for $\mathrm{AA}+\mathrm{DE}$ and $\mathrm{AA}+\mathrm{IPA}$ are fitted to experimental data of [7] (system: AA+DE) and [8] (system: AA+IPA). The solvents of the process concepts considered for the rigorous simulation (diethyl ether (DE), ethyl acetate (EA), isopropyl acetate (IPA), and methyl tert-butyl ether (MTBE)) form heteroazeotropes with $\mathrm{W}$. The parameters for $\mathrm{W}+\mathrm{DE}$ and $\mathrm{W}+\mathrm{IPA}$ are adopted from the Aspen Plus data base [2]. The azeotropes calculated with these parameters are in good agreement with the experimental data of the azeotrope used for the MLT models (cf. Table 3). For the system W+MTBE the UNIQUAC parameters are fitted using the experimental data given by [9]. In Figure 1 the calculated vapor-liquid-liquid equilibrium for $\mathrm{W}+\mathrm{MTBE}$ and the experimental data are depicted. The calculated azeotropic data are given in Table 3. For the VLE AA+MTBE neither parameters nor experimental data are found in the literature. Hence, the UNIQUAC parameters AA+MTBE are adopted form the ternary LLE $\mathrm{W}+\mathrm{AA}+\mathrm{MTBE}$ given in [3]. The UNIQUAC parameters and 
the dimerization constant of AA are reported in Table 4.

Table 3: Azeotropic data in the binary mixture Water (W)+solvent (S) calculated with Aspen Plus using the UNIQUAC parameters listed in Table 1 and 4.

\begin{tabular}{lcc}
\hline & $t_{\mathrm{W}+\mathrm{S}}^{\text {Azeo, Aspen Plus }} /{ }^{\circ} \mathrm{C}$ & $x_{\mathrm{W}}^{\text {Azeo, Aspen Plus }}$ \\
\hline Diethyl ether & 34.0 & 0.052 \\
Ethyl acetate & 71.2 & 0.317 \\
Isopropyl acetate & 76.6 & 0.405 \\
Methyl tert-butyl ether & 52.8 & 0.140 \\
\hline
\end{tabular}

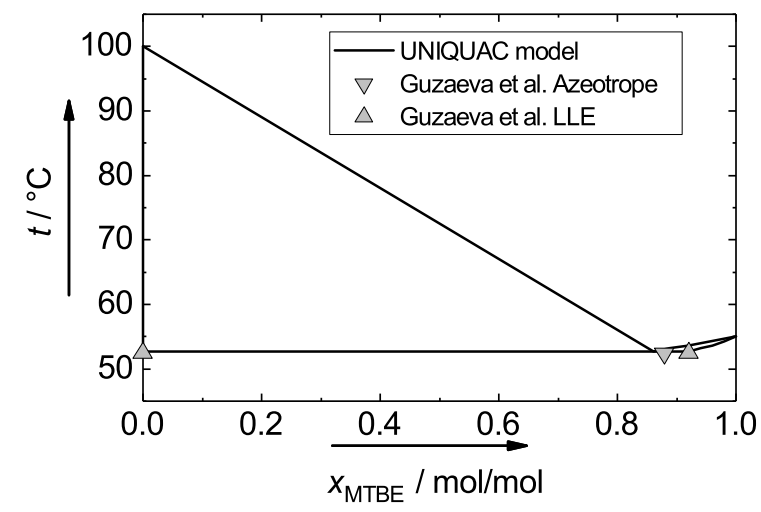

Figure 1: Vapor-liquid-liquid equilibrium of the binary mixture water and methyl tert-butyl ether (MTBE) at 1.013 bar. Curve: UNIQUAC model fitted using the experimental data given by $[9]$. 
Table 4: UNIQUAC parameters $\left(\tau_{i j}=a_{i j}+b_{i j} / T\right)$ and dimerization constant $\left(K_{\mathrm{AA}}\right)$ for the modeling of the vapor-liquid equilibrium of the ternary mixture water $(\mathrm{W})+$ acetic acid (AA) and the solvents diethyl ether (DE), ethyl acetate (EA), isopropyl acetate (IPA), and methyl tert-butyl ether (MTBE). For the UNIQUAC pure component parameters see Table 1 . The dimerization constant for $\mathrm{W}+\mathrm{AA}[6]$ was also suggested for the binary mixtures solvent + AA.

Dimerization constant AA [6] $\ln K_{\mathrm{AA}}=-19.1001+7928.7 /(T / \mathrm{K})$ Binary UNIQUAC parameters

\begin{tabular}{llccccc} 
Component $i$ & Component $j$ & $a_{i j}$ & $a_{j i}$ & $b_{i j} / \mathrm{K}$ & $b_{j i} / \mathrm{K}$ & source \\
\hline AA & $\mathrm{W}$ & 0 & 0 & 257.91 & -585.41 & fitted to [4] and [5] \\
\hline AA & DE & 0 & 0 & 187.35 & -420.62 & fitted to [7] \\
DE & W & 0 & 0 & -620.33 & -76.76 & adopted from [2] \\
\hline AA & EA & 0 & 0 & 175.5947 & 95.3069 & adopted from [2] \\
EA & W & 0 & 0 & -381.2306 & -76.309 & adopted from [2] \\
\hline AA & IPA & 0 & 0 & 236.71 & -637.96 & fitted to [8] \\
IPA & W & 1.858 & -1.907 & -1087.48 & 236.54 & adopted from [2] \\
\hline AA & MTBE & 0 & 0 & 302.96 & -462.25 & LLE parameters adopted from [3] \\
MTBE & W & 0 & 0 & -402.84 & -333.92 & fitted to [9] \\
\hline
\end{tabular}

\section{Rigorous process simulation}

To obtain a rigorous process simulation in Step 7 of the hierarchical approach a two-step procedure is carried out.

In Step A the following specifications are used:

- Number of stages for extraction column: $N^{\mathrm{E} 1}=30$

- Number of stages for distillation columns: $N^{\mathrm{C} 1}=N^{\mathrm{C} 2}=40$

- Feed stage for distillation columns: $N^{\mathrm{C} 1, \text { Feed }}=N^{\mathrm{C} 2 \text {,Feed }}=20$

- Reflux ratio for distillation columns: $R^{\mathrm{C} 1}=R^{\mathrm{C} 2}=10$

- Flow rate stream 2: $\dot{n}^{(2)}$

- Flow rate stream $6: \dot{n}^{(6)}=0.127 \mathrm{kmol} / \mathrm{h}$. 
The flow rates of stream $2\left(\dot{n}^{(2)}\right)$ for the different solvents are adopted from the MLT optimization procedure (cf. Table 7 ). To simplify convergence, the composition and flow rate of all process streams obtained with the MLT models are used as starting values in the simulations. Although containing a recycle, and thus a tear stream, the simulations converged without further ado. The stream tables of the convergent simulations in Step A are given in Table 8.

In Step B, the stage numbers and reflux ratios are optimized. For this purpose the previous specifications are replaced by the following:

a) mole fraction $\mathrm{AA}$ in stream 3: $x_{\mathrm{AA}}^{(3)} \leq 0.001 \mathrm{~mol} / \mathrm{mol}$

b) purity $\mathrm{W}$ in stream $5: x_{\mathrm{W}}^{(5)}=0.999 \mathrm{~mol} / \mathrm{mol}$

c) mole fraction AA in stream 7: $x_{\mathrm{AA}}^{(7)}=1 \cdot 10^{-6} \mathrm{~mol} / \mathrm{mol}$

d) purity AA in stream 6: $x_{\mathrm{AA}}^{(6)}=0.999 \mathrm{~mol} / \mathrm{mol}$

e) mole fraction AA in stream 8: $x_{\mathrm{AA}}^{(8)}=0.001 \mathrm{~mol} / \mathrm{mol}$

To compensate solvent-loss, a make-up stream of pure solvent is fed to the process and mixed with stream 9. The column heights are determined in a sequential procedure. First, the height of E1 is reduced as long as specification a) holds. Second, NQ-curves are calculated for the columns C1 and C2 (cf. Figure 2). For column C1 the specification b) and c), for column column C2 specification d) and e) are applied. The minimum energy demand for the columns $\dot{Q}^{\text {Reboiler, min }}$ are listed in Tabel 5. The number of stages for the columns are chosen such that $\dot{Q}^{\text {Reboiler }}=1.5 \cdot \dot{Q}^{\text {Reboiler, min }}$. The stream tables for the remaining process concepts after Step B is given in Tabel 9. 

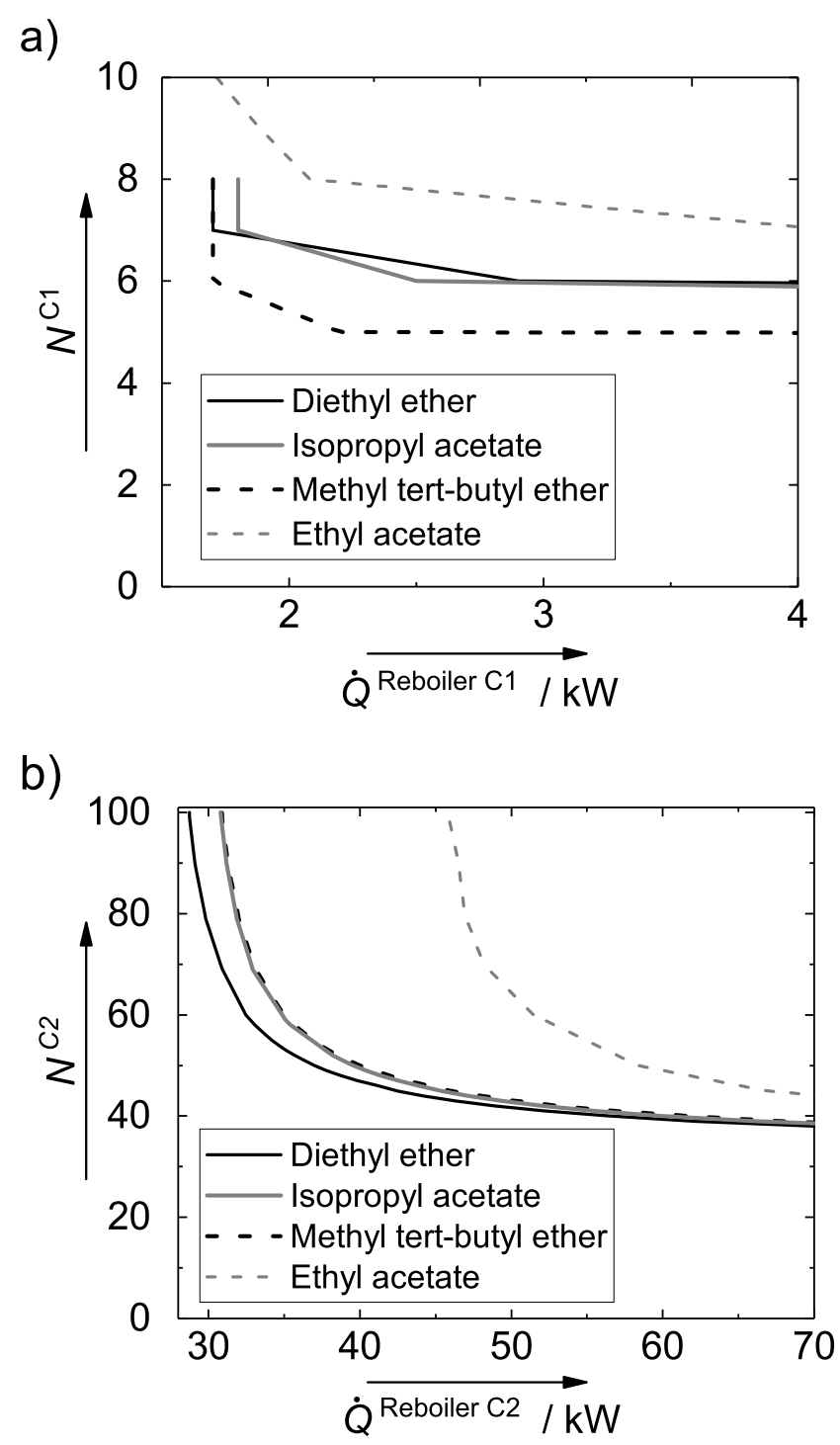

Figure 2: NQ-curves: a) column $\mathrm{C} 1$ with the specifications $x_{\mathrm{W}}^{(5)}=0.999 \mathrm{~mol} / \mathrm{mol}$ and $x_{\mathrm{AA}}^{(7)}=1 \cdot 10^{-6} \mathrm{~mol} / \mathrm{mol}$. b) column $\mathrm{C} 2$ with the specifications $x_{\mathrm{AA}}^{(6)}=0.999 \mathrm{~mol} / \mathrm{mol}$ and $x_{\mathrm{AA}}^{(8)}=0.001 \mathrm{~mol} / \mathrm{mol}$. 
Table 5: Minimum energy demand $\dot{Q}^{\text {Reboiler, min }}$ for the distillation columns C1 and C2 of the process concepts containing Flowsheet II with the solvents diethyl ether, ethyl acetate, isopropyl acetate, and methyl tert-butyl ether. Column $\mathrm{C} 1$ with $N^{\mathrm{C} 1}=8$ stages, Column C2 with $N^{\mathrm{C} 2}=100$ stages.

\begin{tabular}{lcc}
\hline & $\dot{Q}^{\text {Reboiler C1,min }} / \mathrm{kW}$ & $\dot{Q}^{\text {Reboiler C2,min }} / \mathrm{kW}$ \\
\hline Diethyl ether & 1.7 & 28.8 \\
Ethyl acetate & $1.7^{\dagger}$ & 45.8 \\
Isopropyl acetate & 1.8 & 30.8 \\
Methyl tert-butyl ether & 1.7 & 30.9 \\
\hline
\end{tabular}

${ }^{\dagger} N^{\mathrm{C} 1}=10$ stages

\subsection{Rigorous process simulation: Flowsheet II and solvent ethyl acetate}

In Step 5 of the hierarchical approach the process concept containing Flowsheet II and the solvent ethyl acetate is discarded. For completeness this process concept is also carried to the next steps of the hierarchical approach. The minimum energy demand $\dot{Q}^{\text {min }}$ to evaporate the columns overhead products exatly once is $\dot{Q}^{\text {min }}=7.9 \mathrm{~kW}$. The following rigorous simulations are performed as described above. In Step A the reflux ratio for the distillation column C2 was set to $R^{\mathrm{C} 2}=15$ to enable a closed simulation. The NQ-curves of the distillation columns and the minimum energy demand of the columns are shown in Figure 2 and Table 5. The optimization results using the rigorous simulation technique are shown in Table 6. The stream tables are given in Table 7 - 9. In Figure 3 the results of the MLT models and the rigorous simulations before the optimization procedure are plotted. 
Table 6: Optimization results using the rigorous simulation technique for the process concept containing Flowsheet II and the solvent ethyl acetate, which was discarded in Step 5 of the hierarchical approach. The purity of the products, stream 5 and stream 6 is $x_{\mathrm{W}}^{(5)}=0.999 \mathrm{~mol} / \mathrm{mol}$ and $x_{\mathrm{AA}}^{(6)}=0.999 \mathrm{~mol} / \mathrm{mol}$.

\begin{tabular}{lc} 
Number of stages E1 $\left(N^{\mathrm{E} 1}\right)$ & 7 \\
Number of stages $\mathrm{C} 1\left(N^{\mathrm{C} 1}\right)$ & 8 \\
Feed stage C1 $\left(N^{\mathrm{C} 1 \text {,Feed }}\right)$ & 2 \\
Number of stages $\mathrm{C} 2\left(N^{\mathrm{C} 2}\right)$ & 45 \\
Feed stage C2 $\left(N^{\mathrm{C} 2 \text {,Feed }}\right)$ & 32 \\
Reflux ratio $\mathrm{C} 1\left(R^{\mathrm{C} 1}\right)$ & 1.9 \\
Reflux ratio $\mathrm{C} 2\left(R^{\mathrm{C} 2}\right)$ & 8.5 \\
Reboiler duty $\mathrm{C} 1\left(\dot{Q}^{\text {Reboiler } \mathrm{C} 1} / k W\right)$ & 2.1 \\
Reboiler duty $\mathrm{C} 2\left(\dot{Q}^{\text {Reboiler } \mathrm{C} 2} / k W\right)$ & 70.7 \\
Flow rate stream $2\left(\dot{n}^{(2)} / \mathrm{kmol} / \mathrm{h}\right)$ & 0.71 \\
Solvent loss $\left(\dot{n}_{\mathrm{S}}^{(5)}+\dot{n}_{\mathrm{S}}^{(6)} / \mathrm{kmol} / \mathrm{h}\right)$ & $1 \cdot 10^{-7}$ \\
\hline
\end{tabular}

\section{Stream tables}

In this chapter the stream tables for the process concepts containing Flowsheet II and the solvents diethyl ether (DE), ethyl acetate (EA), isopropyl acetate (IPA), and methyl tert-butyl ether (MTBE) are given: Table 7: Stream tables obtained from the MLT optimization procedure. Table 8: Stream tables obtained from the rigorous simulation after Step A. Figure 3: Comparison of the MLT results with the results from the rigorous simulation after Step A. Table 9: Stream tables obtained from the the rigorous simulation after Step B. 


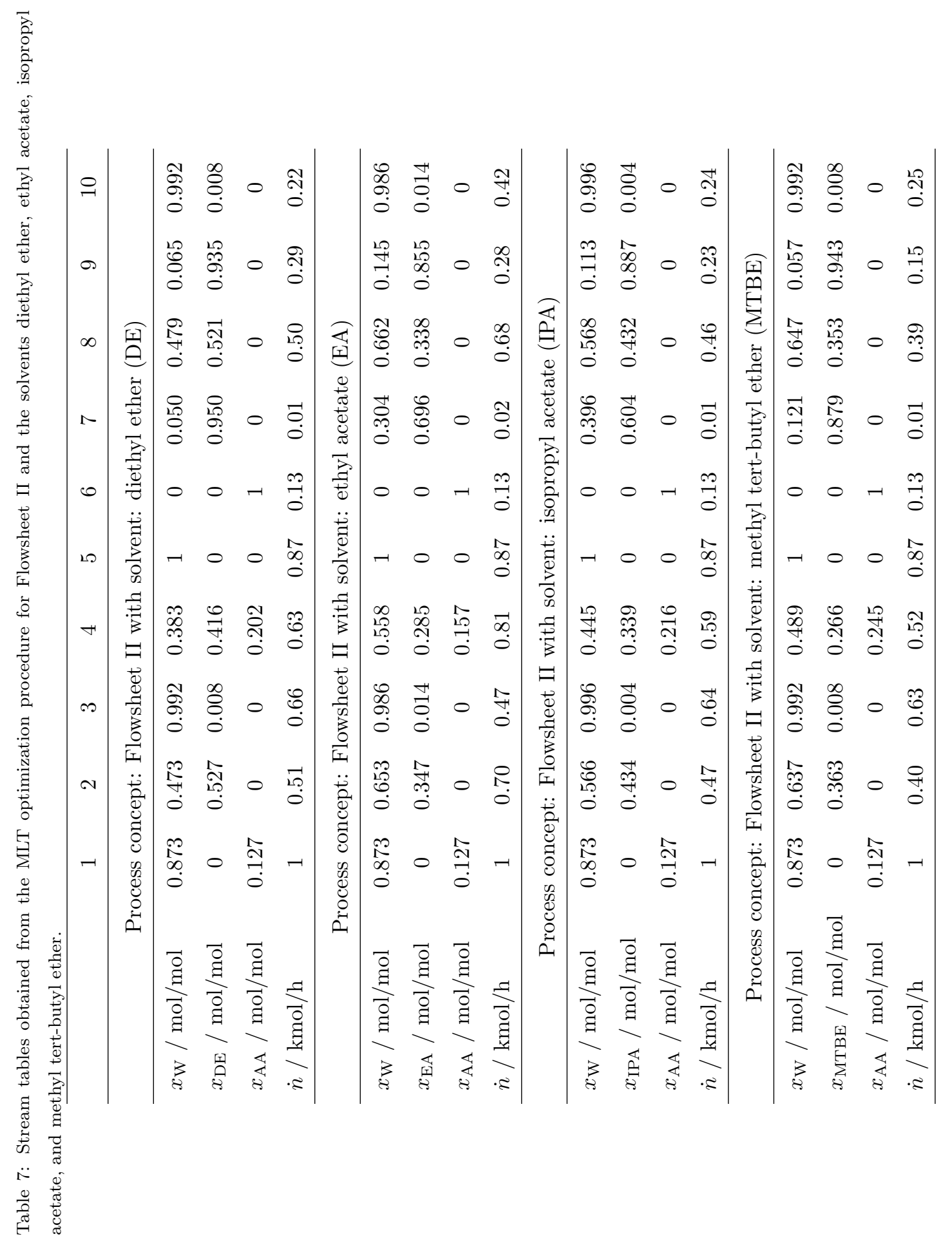




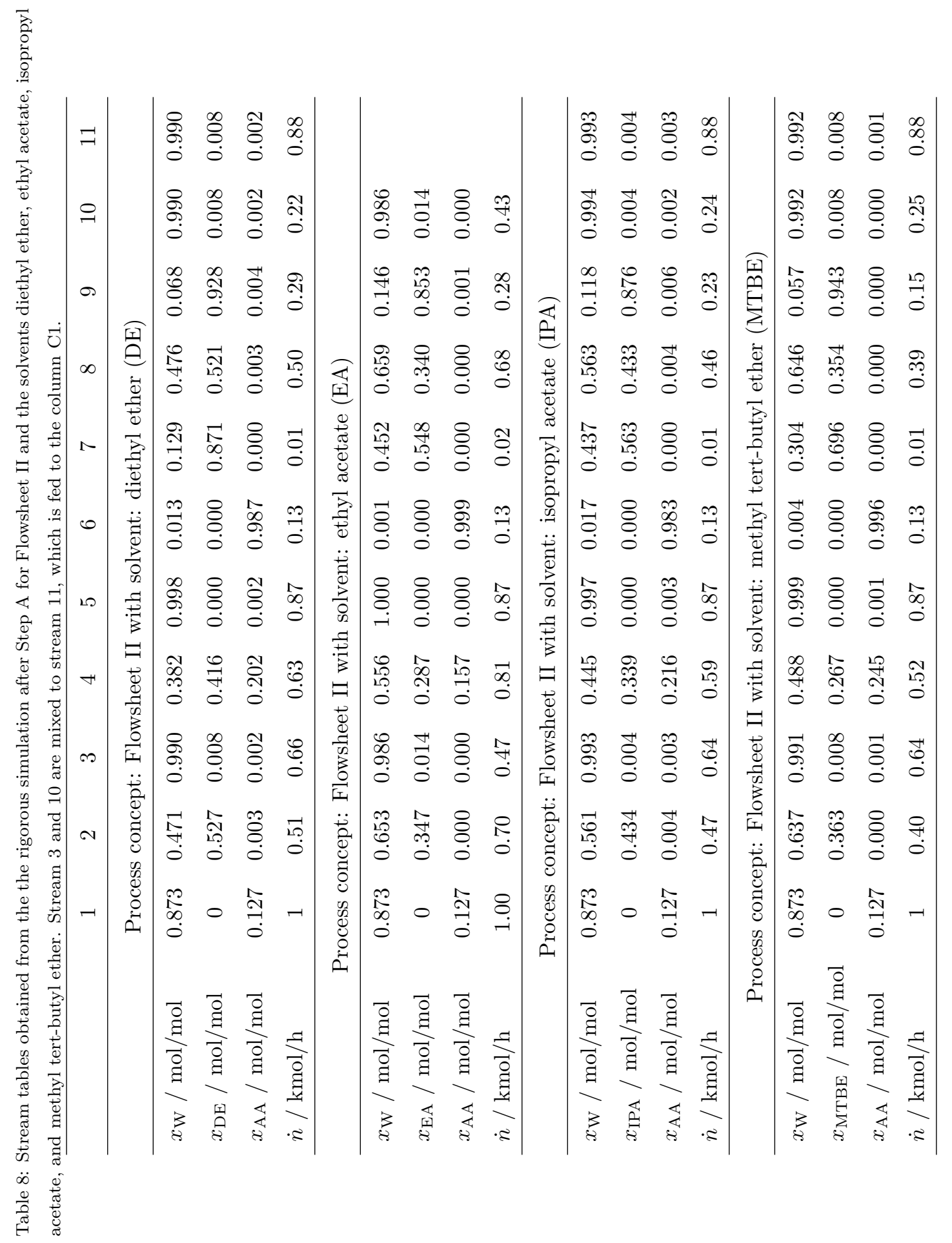



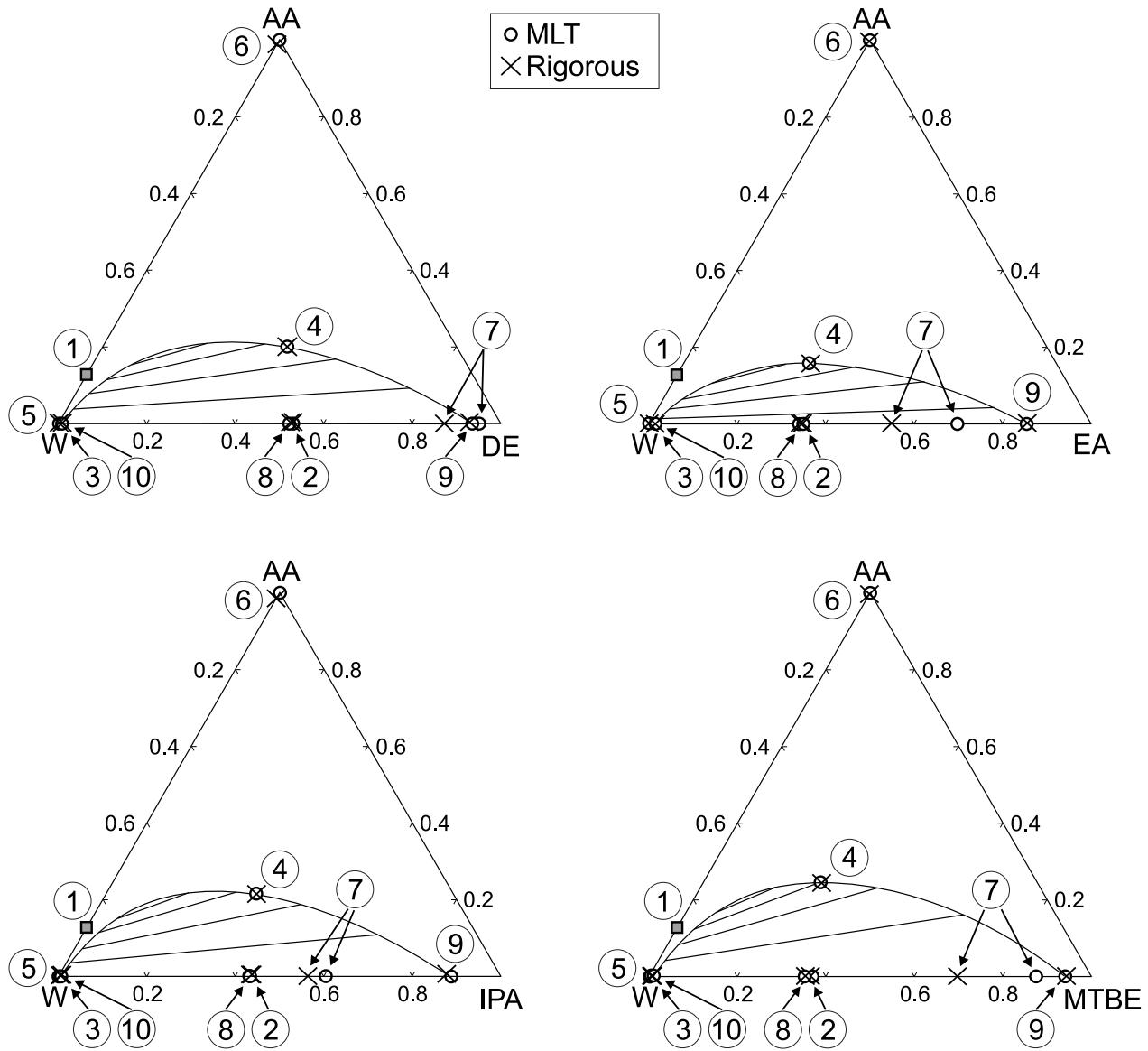

Figure 3: Comparison of the results for the the process simulations using MLT models (Table 7) and Aspen Plus (Table 8). Flowsheet II with the solvents diethyl ether (DE), ethyl acetate (EA), isopropyl acetate (IPA), and methyl tert-butyl ether (MTBE). Because of clarity, the azeotropes in the mixtures $\mathrm{W}+$ solvent are not depicted. Concentrations are in $\mathrm{mol} / \mathrm{mol}$. 


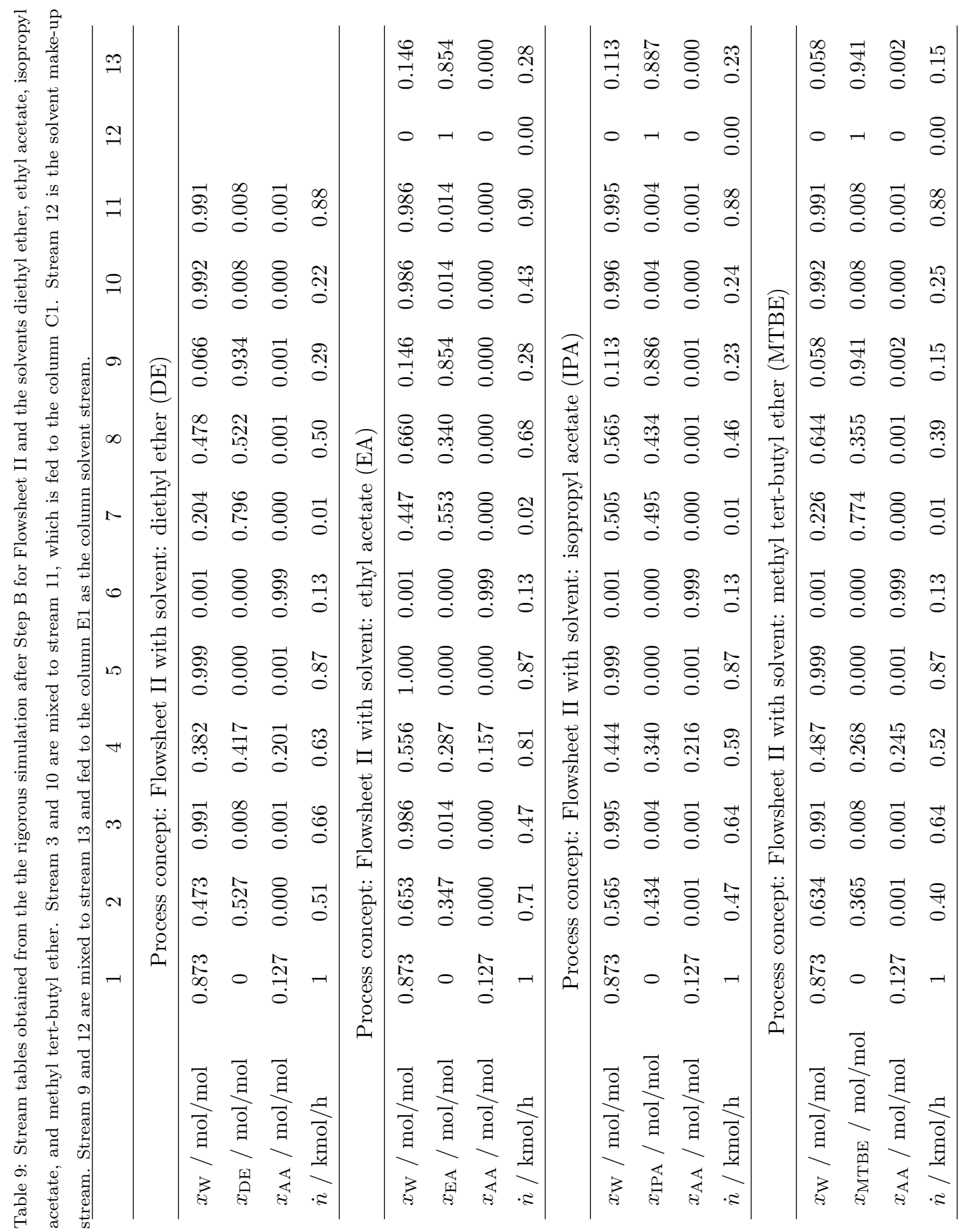




\section{References}

[1] J. M. Sorensen, W. Arlt, Liquid-liquid Equilibrium Data Collection: Ternary Systems (Dechema Chemistry Data Vol. V Part 2), DECHEMA: Frankfurt, 1980.

[2] AspenPlus V8.4, Aspen Technology, Inc., Cambridge, USA, 2013.

[3] X. Miao, H. Zhang, T. Wang, M. He, Liquid-Liquid Equilibria of the Ternary System Water + Acetic Acid + Methyl tert-Butyl Ether, Journal of Chemical \& Engineering Data 52 (3) (2007) 789-793. doi:10.1021/je060409p.

[4] D. F. Othmer, S. J. Silvis, A. Spiel, Composition of Vapors from Boiling Binary Solutions: Pressure Equilibrium Still for Studying WaterAcetic Acid System, Industrial \& Engineering Chemistry 44 (8) (1952) 1864-1872. doi:10.1021/ie50512a041.

[5] I. Brown, A. Ewald, Liquid-Vapour Equilibria Equilibria .1. The Systems Carbon Tetrachloride-Cyclohexane and Water - Acetic Acid, Australian Journal of Scientific Research Series A-Physical Sciences 3 (1950) 306-323.

[6] R. Büttner, G. Maurer, Dimerisierung einiger organischer Säuren in der Gasphase, Berichte der Bunsengesellschaft für physikalische Chemie 87 (10) (1983) 877-882. doi:10.1002/bbpc.19830871010.

[7] E. Bonauguri, Z. Carpani, D. Dall'Orto, Sul sistema ternario acido aceticoacqua-etere dietilico Parte II. Curve di equilibrio a pressione atmosferica dei sistemi binari; curve di distillazione, di ebollizione e di rugiada del sistema ternario, La Chimica e l'Industria 38 (9) (1956) 768-777.

[8] W. Chang, G. Guan, X. Li, H. Yao, Isobaric Vapor-Liquid Equilibria for Water + Acetic Acid + (n-Pentyl Acetate or Isopropyl Acetate), Journal of Chemical \& Engineering Data 50 (4) (2005) 1129-1133. doi:10.1021/je049711t. 
[9] T. Guzaeva, O. Gorbacheva, L. Kostikova, A. Mozzhukhin, A. Solokhin, M. Fukas, Study of Vapor-Liquid Equilibrium in Binary Components of Isoprene Production Mixtures, Oniitekhim (1981) 127-133. 